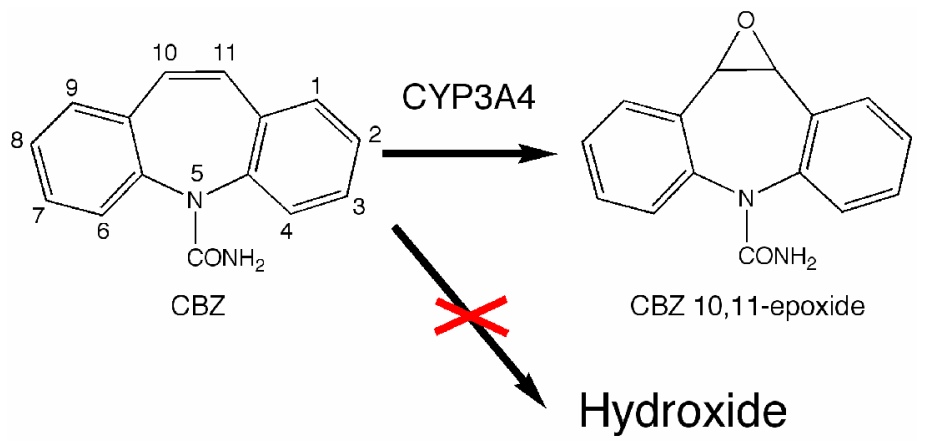

To clarify the reason why CYP3A4 produces an epoxide rather than a hydroxide, the mechanism of epoxidation of carbamazepine (CBZ) by CYP3A4 was investigated by theoretical calculations. 


\section{An Epoxidation Mechanism of Carbamazepine}

\section{by CYP3A4}

Masayuki Hata, ${ }^{*}$, Yoshikazu Tanaka, ${ }^{a}$ Naoko Kyoda, ${ }^{a}$ Taisuke Osakabe, ${ }^{a}$ Hitomi Yuki, ${ }^{a}$ Itsuko Ishii, ${ }^{a}$ Mitsukazu Kitada, ${ }^{b}$ Saburo Neya ${ }^{a}$ and Tyuji Hoshino ${ }^{a}$

${ }^{a}$ Graduate School of Pharmaceutical Sciences, Chiba University, 1-33 Yayoi-cho, Inage-ku, Chiba 263-8522, Japan

${ }^{\mathrm{b}}$ Division of Pharmacy, Chiba University Hospital, 1-8-1 Inohana, Chuo-ku, Chiba 260-8677, Japan

\footnotetext{
*CORRESPONDING AUTHOR

Phone: $+81-89-926-7265$

Fax: $+81-89-926-7162$

E-mail: mhata@cc.matsuyama-u.ac.jp

${ }^{\S}$ CURRENT ADDRESS

College of Pharmaceutical Sciences, Matsuyama University

4-2 Bunkyo-cho, Matsuyama 790-8578, Japan
} 


\begin{abstract}
Human CYP3A4 catalyzes the 10,11-epoxidation of carbamazepine (CBZ). However, the epoxide is less stable in terms of potential energy than hydroxides of the six-membered aromatic ring. To clarify the reason why CYP3A4 produces such an energetically unfavorable compound, the mechanism of epoxidation of CBZ by CYP3A4 was investigated by theoretical calculations. The reaction consisted of two elementary processes in which two C-O bonds were generated stepwise. The rate-determining step was the first one and the activation energy was $21.3 \mathrm{kcal} / \mathrm{mol}$ at the DFT $\left(\mathrm{B} 3 \mathrm{LYP} / 6-31 \mathrm{G}^{* *}\right)$ level. The activation energy level of the first step of the 10,11-epoxidation was lower than that of the hydroxylation of the aromatic ring. For this reason, 10,11-epoxidation is more probable than hydroxylation of the aromatic ring and only 10,11-epoxide is formed.
\end{abstract}

\title{
Keywords
}

density functional theory

hydroxylation

potential energy

rate-determining step 


\section{Introduction}

Cytochrome P450 (CYP) exists in most living creatures, including animals, plants and microorganisms, and plays an important role in metabolism. ${ }^{1,2}$ The enzymes contribute to metabolism by oxygenating many kinds of aromatic and aliphatic substrates, so-called monooxygenation reaction. The monooxygenation reaction by CYP is initiated by substrate binding to ferric P450 followed by spin state conversion. ${ }^{3}$ When an electron (1st $\left.\mathrm{e}^{-}\right)$is introduced into the substrate-bound P450, the heme iron is converted into the reduced form, $\mathrm{Fe}^{2+}$, and then an $\mathrm{O}_{2}$ molecule is incorporated in the heme pocket. When another electron (2nd $\mathrm{e}^{-}$) is introduced, the $\mathrm{O}_{2}$ molecule becomes very reactive and the substrate will be oxygenated by an insertion of one $\mathrm{O}$ atom into the $\mathrm{R}-\mathrm{H}$ bond.

There have been many experimental and theoretical investigations of the monooxygenation mechanism by CYP. ${ }^{1,4,5}$ However, most theoretical investigations handled the monooxygenation mechanisms by cytochrome P450cam (CYP101) and other water-soluble CYPs produced by microorganisms. ${ }^{6-10}$ Recently, many experimentally ${ }^{11-22}$ or theoretically determined structures ${ }^{23-26}$ of mammalian microsomal CYPs have been provided, and detailed structural study of these CYPs has become possible. Furthermore, these structures are expected to be utilized for prediction of the metabolizing site of a candidate for a novel drug by human CYPs.

We focused on human CYP3A4 in this study. Human CYP3A4 is a major hepatic and intestinal enzyme and is one of the most important enzymes for drug metabolism. ${ }^{27}$ It oxidizes more than half of the medicines that are metabolized by CYP, especially macrolides, steroids and anti-epilepsy medicines. ${ }^{28,29}$ Thus, investigation of the mechanism of drug metabolism by human CYP3A4 is important and will be helpful for the development of various types of pharmaceutics in the future. 
The enzyme metabolizes carbamazepine (CBZ), an anti-epilepsy drug. The sole metabolite is 10,11 -epoxide (Scheme 1). ${ }^{28,30,31}$ However, the epoxide is less stable in terms of potential energy than hydroxides of the six-membered aromatic ring; i.e., the epoxide has about 20 $\mathrm{kcal} / \mathrm{mol}$ larger potential energy than the hydroxides (Table 1) whose energies were obtained by the density functional theory (DFT) at the B3LYP/6-31G** level using the Gaussian 98 program package. ${ }^{32}$ There are four metabolic pathways for CBZ; i.e., epoxidation of the 10,11 double bond of the azepine ring, hydroxylation of six-membered aromatic rings, direct $\mathrm{N}$-glucuronidation at the carbamoyl group and substitution of the six-membered rings with sulfur-containing groups. ${ }^{33}$ Though CYPs involve the former two pathways, CYP3A4 catalyzes only epoxidation against CBZ. Why does CYP3A4 produce an epoxide, not a hydroxide? In this study, the mechanism of epoxidation of CBZ by CYP3A4 was investigated by theoretical calculations. We constructed models for calculation and drew a potential energy profile of the epoxidation. Our computational results elucidated the hydroxylation mechanism and clarified the reason why the epoxidation occurs easier than the hydroxylation. 


\section{Results}

2.1. Energy-minimized structure of CYP3A4-CBZ complex. The active site of the energy-minimized structure of CYP3A4-CBZ complex is shown in Fig. 1. An oxygen atom at the distal ligand binding site of compound I (O1) interacted with the epoxidation site of CBZ. The distance between $\mathrm{O} 1$ atom and $\mathrm{C} 10$ atom of CBZ was $3.39 \AA$, which is shorter than that between $\mathrm{O} 1$ and $\mathrm{C} 11$ atoms (4.00 $\AA$ ). The carbonyl oxygen atom of Phe304 interacted with the nitrogen atom in the carbamoyl group of CBZ. This interaction was hydrogen bond; i.e., the distances between $\mathrm{O}$ atom of Phe 304 and $\mathrm{N}$ and $\mathrm{H} 2$ atoms of $\mathrm{CBZ}$ were $2.80 \AA$ and 1.84 $\AA$, respectively. This result suggests that Phe304 is involved in the epoxidation of CBZ by CYP3A4. To clarify the role of Phe304, the CBZ epoxidation mechanism in which Phe304 is involved was investigated by using the DFT method in the following.

2.2. CBZ epoxidation mechanism by CYP3A4. The model for elucidation of the epoxidation mechanism was constructed as described in section 5.2.1. and DFT calculations in both the doublet and quartet states were performed using the model.

2.2.1. Epoxidation in the doublet state. From the results of $\mathrm{MM}$ calculation, $\mathrm{O} 1$ atom is likely to be bound to $\mathrm{C} 10$ atom rather than $\mathrm{C} 11$ atom because the $\mathrm{C} 10-\mathrm{O} 1$ distance was shorter than the C11-O1 distance. The C10-O1 bond formation mechanism was therefore firstly examined. Changes in potential energy, structure and spin density distribution are shown in Figs. 2(a) and 3 and Tables 2 and 3, respectively. In the initial structure (D1), O1 atom interacted with the epoxidation site of CBZ: C10 and C11 atoms, at distances of $2.89 \AA$ and $3.40 \AA$, respectively. A carbonyl oxygen atom of Phe304 (O) interacted with a carbamoyl nitrogen atom of CBZ (NH) by a hydrogen bond (NH-O: $2.83 \AA$, H2-O: $1.97 \AA$ ). Spin density of $\mathrm{O} 1$ atom was 0.62 , which suggested a character of a free radical. ${ }^{34}$ When the $\mathrm{C} 10-\mathrm{O} 1$ distance was shortened, the potential energy increased and a transition state (TS) structure 
appeared (Fig. 3(D2)). The C10-O1 and C11-O1 distances shortened at $2.10 \AA$ and $2.78 \AA$, respectively, whereas the Fe-O1 distance lengthened from $1.61 \AA$ of the initial structure to $1.70 \AA$. The $\mathrm{C} 10-\mathrm{C} 11$ bond slightly lengthened at $1.39 \AA$ from the initial structure $(1.35 \AA)$. Passing the TS, the C10-O1 distance shortened further and an intermediate structure (D3) was formed, generating a covalent bond of C10-O1 (Fig. 3). In structure (D3), both the Fe-O1 and the $\mathrm{C} 10-\mathrm{C} 11$ distances further lengthened to $1.82 \AA$ and $1.49 \AA$, respectively, from the TS (D2). The C11-O1 distance was $2.46 \AA$, which implied an interaction between the two atoms. The NH-O and $\mathrm{H} 2-\mathrm{O}$ distances were kept to the hydrogen bond distance through the reaction (Fig. 3 and Table 2). Though the spin density in structure (D1) was localized at O1, heme Fe and Cys442, it moved to the substrate with advance of the reaction and finally concentrated at the heme Fe atom and CBZ, especially C11 atom, in structure (D3) (Table 3). This reaction was the rate-determining step of the epoxidation of CBZ by CYP3A4 in the doublet state, which imposed an estimated activation energy of $13.8 \mathrm{kcal} / \mathrm{mol}$ (Fig. 2(a)).

From structure (D3), a covalent bond between $\mathrm{O} 1$ and $\mathrm{C} 11$ atoms is formed to complete the epoxidation. Since $\mathrm{O} 1$ atom interacted with $\mathrm{C} 11$ atom in structure (D3) (2.46 $\AA$ ), it is expected that the next reaction occurs smoothly. Changes in potential energy, structure and spin density distribution are shown in Figs. 2(b) and 3 and Tables 2 and 3, respectively. When the C11-O1 distance shortened, potential energy slightly increased and the second TS structure (D4) appeared. The C11-O1 distance was $2.11 \AA$ in structure (D4). The Fe-O1 distance was $1.87 \AA$, indicating that detachment of $\mathrm{O} 1$ atom from compound I proceeded with the formation of an epoxide. The $\mathrm{C} 10-\mathrm{O} 1$ and $\mathrm{C} 10-\mathrm{C} 11$ distances temporarily became the least in structure (D4). Spin density of Fe atom and CBZ (C11 atom) together decreased from the values of structure (D3). Passing the TS, C11 and O1 atoms were bonded and an epoxide was formed (Fig. 3(D5)). The Fe-O1 distance further lengthened from structure (D4) and became $2.25 \AA$. The $\mathrm{C} 10-\mathrm{O} 1$ and $\mathrm{C} 10-\mathrm{C} 11$ distances lengthened again. The NH-O and H2-O 
distances were kept to the hydrogen bond distance through the reaction (Table 2). Spin density of structure (D5) concentrated at the heme Fe atom (1.09). The estimated activation energy of this reaction was $7.8 \mathrm{kcal} / \mathrm{mol}$ and the potential energy of structure (D5) was 7.8 $\mathrm{kcal} / \mathrm{mol}$ more stable from that of the initial structure (D1) (Fig. 2).

2.2.2. Epoxidation in the quartet state. The epoxidation mechanism in the quartet state was analyzed in the same way as that in the doublet state. Changes in potential energy, structure and spin density distribution are shown in Figs. 4 and 5 and Tables 4 and 5, respectively. In the initial structure (Q1), O1 atom of compound I interacted with the epoxidation site of CBZ: C10 and C11 atoms, at distances of $2.88 \AA$ and $3.40 \AA$, respectively. A carbonyl oxygen atom of Phe304 (O) interacted with a carbamoyl nitrogen atom of CBZ (NH) by a hydrogen bond (NH-O: $2.83 \AA$, H2-O: $1.97 \AA$ ). Spin density of O1 atom was 0.65. In the first TS structure (Q2), the C10-O1 and C11-O1 distances shortened at $1.98 \AA$ and 2.71 $\AA$, respectively, whereas the Fe-O1 distance lengthened from $1.61 \AA$ of the initial structure to 1.67 $\AA$. The C10-C11 bond slightly lengthened at $1.39 \AA$ from the initial structure $(1.35 \AA)$. In the intermediate structure (Q3), a covalent bond of $\mathrm{C} 10-\mathrm{O} 1$ was formed. Both the Fe-O1 and the $\mathrm{C} 10-\mathrm{C} 11$ distances further lengthened to $1.84 \AA$ and $1.50 \AA$, respectively, from the TS (Q2). The C11-O1 distance was $2.47 \AA$, which suggested an interaction between the two atoms. The NH-O and H2-O distances were kept to the hydrogen bond distance through the reaction (Fig. 5, Table 4). Though spin density in structure (Q1) was also localized at O1, heme Fe and Cys442, it moved to the substrate with advance of the reaction and finally concentrated at the heme Fe atom and CBZ, especially C11 atom, in structure (Q3) (Table 5). Due to remarkable concentration of spin density to heme Fe, Cys442 had $\beta$ spin density in Structure (Q3), whereas $\alpha$ spin density located in the other structures. This reaction was the rate-determining step, which gave an estimated activation energy of $22.6 \mathrm{kcal} / \mathrm{mol}$ (Fig. 4(a)). 
From structure (Q3), when the C11-O1 distance shortened, potential energy slightly increased and the second TS structure (Q4) appeared. The C11-O1 distance was $2.10 \AA$. The Fe-O1 distance was $2.12 \AA$, indicating that detachment of $\mathrm{O} 1$ atom from compound I proceeded with the formation of an epoxide. The $\mathrm{C} 10-\mathrm{O} 1$ and $\mathrm{C} 10-\mathrm{C} 11$ distances once shortened slightly from structure (Q3). Spin density of Fe atom and CBZ (C11 atom) together decreased from the values of structure (Q3) (Table 5). In the final structure (Q5), the Fe-O1 distance further lengthened from structure (Q4) and became $2.94 \AA$. The C10-O1 and C10C11 distances lengthened again. The NH-O and H2-O distances were kept to the hydrogen bond distance through the reaction (Fig. 5 and Table 4). Spin density of structure (Q5) concentrated at the heme Fe atom (2.69) and Cys442 (0.36). The estimated activation energy of this reaction was $6.9 \mathrm{kcal} / \mathrm{mol}$ and the potential energy of structure (Q5) was $9.8 \mathrm{kcal} / \mathrm{mol}$ more stable from that of the initial structure (Q1) (Fig. 4(b)). 


\section{Discussion}

The CBZ 10,11-epoxidation mechanism by CYP3A4 in which Phe304 is involved was clarified in this study. CYP3A4 binds CBZ in its active site to cause the 10,11-epoxidation. Phe304 and Ala305, which are located at the nearest position from the heme Fe atom, are important for the reaction. The results of MM calculation show that these residues hold the substrate stably (Fig. 1). Thus, the active site of CYP3A4 has sufficient capacity to accommodate $\mathrm{CBZ}$ and has the ability to set $\mathrm{CBZ}$ in an appropriate position to make the 10,11-epoxidation possible. The epoxidation process is a two-step reaction, and the ratedetermining step is the first one in both the doublet and quartet states. There is almost no difference in the overall structural changes between the doublet and quartet cases except the Fe-O1 distance in the second elementary step. The distances between $\mathrm{O} 1$ and Fe atoms in the TS are $1.87 \AA$ and $2.12 \AA$ for the doublet and quartet states, respectively, and they are $2.25 \AA$ and $2.94 \AA$, respectively, in the final structure (Tables 2 and 4). In spite of the difference in total spin multiplicity, the spin density change in the substrate (CBZ), especially $\mathrm{C} 11$ atom, was similar in the doublet and quartet cases (Tables 3 and 5); i.e., the absolute values of spin density increased in the first step, whereas they decreased in the second step. Hata et al. elucidated the monooxygenetion mechanism by CYP using the DFT method. ${ }^{34}$ Although the reaction in their study was a hydroxylation reaction, the overall change in spin density is similar to that of the present CBZ 10,11-epoxidation.

In the following sections, the reaction mechanism will be discussed in detail.

3.1. One-step epoxidation of CBZ by CYP3A4. The one-step epoxidation of CBZ by CYP3A4 was also elucidated by theoretical calculations. The results in the doublet state are shown in Figs. 6(a) and 7 and Table 6(a). In the initial structure (D6), CBZ was held by the carbonyl group of Phe304 by a hydrogen bond (NH-O: $2.84 \AA$, H2-O: $1.94 \AA$ ). An oxygen atom of compound I interacted with $\mathrm{C} 10$ and $\mathrm{C} 11$ atoms of CBZ, whose distances were ca. 2.9 
$\AA$ each. When the distance between $\mathrm{O} 1$ and $\mathrm{C} 10$ and that between $\mathrm{O} 1$ and $\mathrm{C} 11$ shortened, a TS structure appeared (D7) at $2.02 \AA$. Both the C10-C11 and Fe-O1 distances lengthened: the former was $1.35 \AA$ to $1.40 \AA$ and the latter was $1.61 \AA$ to $1.78 \AA$. After passing the TS, O1 was bound to both $\mathrm{C} 10$ and $\mathrm{C} 11$ and an epoxide was produced (D8). Both the C10-C11 and Fe-O1 distances lengthened: the former was $1.40 \AA$ to $1.48 \AA$ and the latter was $1.78 \AA$ to 2.37 A. The hydrogen bond between CBZ and Phe304 was maintained through the reaction. The results in the quartet state are shown in Figs. 6(b) and 8 and Table 6(b). The structural changes in the quartet state were similar to those in the doublet state. A noticeable difference was the Fe-O distance in the final structure; i.e., it was $2.37 \AA$ in the doublet state, whereas it was $3.16 \AA$ in the quartet state. The estimated activation energies in the doublet and quartet states were $20.0 \mathrm{kcal} / \mathrm{mol}$ and $37.0 \mathrm{kcal} / \mathrm{mol}$, respectively, and were much larger than those of the rate-determining step of the two-step reaction $(13.8 \mathrm{kcal} / \mathrm{mol}$ in the doublet state and 22.6 $\mathrm{kcal} / \mathrm{mol}$ in the quartet state). Thus, it can be concluded that the CBZ epoxidation by CYP3A4 proceeds in a two-step process.

3.2. Potential energy change in the epoxidation of CBZ by CYP3A4. As shown in the results section, the estimated activation energies of the $\mathrm{CBZ}$ epoxidation by CYP3A4 in the doublet and quartet states are $13.8 \mathrm{kcal} / \mathrm{mol}$ and $22.6 \mathrm{kcal} / \mathrm{mol}$, respectively. Filatov et al. proposed the TSR mechanism in which a potential energy crossing between the high-spin (quartet) and the low-spin (doublet) states occurs and a low-spin state structure is produced in the substrate oxidation of P450 ferryl complex. ${ }^{35-47}$ A potential energy diagram is presented in Fig. 9 to summarize our results in both the doublet and quartet states and to examine the possibility of spin-state crossing. The quartet state is more stable than the doublet state in the initial structure, whereas the doublet state becomes more stable in the transition state of the first elementary step and the intermediate: i.e., this suggests that spin-state crossing occurred during the reaction. According to Filatov's results, the quartet state was slightly more stable 
than the doublet one in the reactant, ${ }^{40}$ but the doublet state was more stable in the product. Although our results showed that the quartet state was stable in both the reactant (Q1) and the product (Q5), our results agree with theirs in the existence of spin-state crossing. With consideration of this spin-state crossing, the estimated activation energy in the rate-limiting step was concluded to be $15.1 \mathrm{kcal} / \mathrm{mol}$ (Fig. 9). This value is similar to that obtained in a previous study. ${ }^{34}$ In order to examine the dependence of the computational accuracy on selection of the basis set, DFT calculations with a higher-order basis set $\left(6-31 \mathrm{G}^{* *}\right)$ were performed on the stationary points and the energies were compared in the same way. The activation energy obtained in the additional calculation was estimated to be $21.3 \mathrm{kcal} / \mathrm{mol}$.

3.3. Potential energy change for hydroxylation of CBZ by CYP3A4. Not only 10,11epoxidation but also hydroxylation of the aromatic ring occurs in the metabolic pathways on CBZ. ${ }^{33}$ Thus, CYP catalyzes the hydroxylation of the substrate. Then, doesn't hydroxylation of CBZ by CYP3A4 occur? The possibility was elucidated by theoretical calculation. The CYP-catalyzed oxygenation of aromatic compounds generates an epoxide intermediate in the early step. ${ }^{1}$ According to the results of theoretical calculations so far and this study, the epoxidation is a two-step reaction and the rate-determining step should be the first one. For this reason, the activation energies for the first step were calculated in the same way as that in the case of 10,11-epoxidation. In the active site of CYP3A4, CBZ can be set in a proper position to be hydroxylated and to interact with Phe304. Considering the distance between O1 atom and a carbon atom of the aromatic ring and the interaction with Phe304, C8 and C9 atoms were regarded to be attacked in hydroxylation. Then, CYP3A4-CBZ complexes were constructed in the same way as that described in the Experimental section and the potential energy profiles were obtained in the same way as that described in the Results section.

The potential energy and structure changes in the C9 attack case are shown in Figs. 10(a) and 11 and Table 7(a). In the case of C8, they are shown in Figs. 10(b) and 12 and Table 7(b). 
The structural changes in the quartet state were similar to those in the doublet state. For this reason, figures and tables of the quartet state are shown in SUPPLEMENTARY MATERIAL (Figs. S1 to S3 and Table S1). In both cases, the O1-C9 (or C8) distances shortened with maintenance of the hydrogen bond between Phe304 and CBZ (Tables 7 and S1) and the epoxide intermediate was formed after passing the TS structure. The activation energies were ca. $20 \mathrm{kcal} / \mathrm{mol}$. Considering the spin-state crossing and employing the higher-order basis set $\left(6-31 \mathrm{G}^{* *}\right)$ (section 3.2), the activation energies for the $\mathrm{C} 9$ and $\mathrm{C} 8$ attack cases were estimated to be $26.9 \mathrm{kcal} / \mathrm{mol}$ and $27.0 \mathrm{kcal} / \mathrm{mol}$, respectively. These activation energies were higher than that for 10,11-epoxidation, which was estimated to be $21.3 \mathrm{kcal} / \mathrm{mol}$. These results suggest that 10,11-epoxidation is more likely to occur than hydroxylation of the aromatic ring in the oxygenation of CBZ by CYP3A4. Although the hydroxides of the aromatic ring are more stable in potential energy than the 10,11-epoxide, 10,11-epoxidation proceeds quickly compared with hydroxylation of the aromatic ring because the activation energy for the first step of 10,11-epoxidation is smaller than that of hydroxylation. For this reason, CBZ 10,11epoxide is the sole product in the metabolism of CBZ by CYP3A4. 


\section{Conclusion}

The 10,11-epoxidation mechanism of CBZ by CYP3A4 in which Phe304 is involved was clarified by theoretical calculations. The reaction consists of two elementary processes and the rate-determining step is the first one: i.e., the $\mathrm{C}-\mathrm{O}$ bond formation. In the active site of CYP3A4, CBZ keeps a hydrogen bond with Phe304 and stays in an appropriate position for the 10,11-epoxidation due to the interaction between the epoxidation site and oxygen atom of compound I. During the reaction, a hydrogen bond between CBZ and Phe304 is maintained. The activation energy level of the first step of 10,11-epoxidation is lower than that of hydroxylation of the aromatic ring. For this reason, 10,11-epoxidation is more likely to occur than hydroxylation of the aromatic ring and only 10,11-epoxide is formed, although 10,11epoxide has a disadvantage in potential energy. 


\section{Experimental}

5.1. Molecular mechanics calculations. First, molecular mechanics (MM) calculations were performed to obtain the structure of CYP3A4-CBZ complex upon epoxidation because such a crystal structure has not been determined yet.

5.1.1. Construction of the enzyme-substrate complex. A few years ago, some x-ray crystallographic coordinates of CYP3A4 were disclosed by two groups. Williams et al. determined a substrate-free form and a substrate (metyrapone or progesterone)-bound form, ${ }^{19}$ whereas Yano et al. determined only a substrate-free form. ${ }^{16}$ However, the latter has higher resolution and less missing residues than the former. Recently, Ekroos and Sjögren disclosed a large substrate (ketoconazole or erythromycin)-bound form of CYP3A4 and showed that the protein underwent dramatic conformational changes upon ligand binding. ${ }^{20} \mathrm{CBZ}$ is not large enough to cause such conformational changes. Moreover, they argued that both metyapone and progesterone are small and may not induce the conformational changes. ${ }^{20}$ Accordingly, the structure determined by Yano et al. (pdbcode: 1TQN) was used for our investigation of the epoxidation mechanism by CYP3A4.

When CYP3A4 epoxidizes a substrate, the enzyme should keep the substrate in an area where the reaction occurs. CBZ can be held by a hydrogen bond because of its carbamoyl side chain. Moreover, according to the x-ray structure, the active site of CYP3A4 has enough space for accommodating CBZ. In this study, Phe304 and Ala305 were selected to hold CBZ because these residues were located at the nearest positions from a heme Fe atom. Phe304 plays an important role in the substrate oxidation of CYP3A4 as shown by the results of a sitedirected mutagenesis. ${ }^{48}$

The model for the MM calculations was constructed in the following way. First, an acetyl group and a $\mathrm{NHCH}_{3}$ group were attached to the N-terminus of His28 and Ser286 and the C- 
terminus of Ser281 and Thr499, respectively, to terminate the missing part of the enzyme. In the monooxygenation reaction by CYP, $\mathrm{O}-\mathrm{O}$ bond cleavage of the $\mathrm{O}_{2}$ molecule at the distal side of heme should occur after introduction of the 2 nd $\mathrm{e}^{-}$. The intermediates are, however, not able to be observed in experiments because this reaction proceeds very quickly. Accordingly, the detailed mechanism of the substrate monooxygenation reaction in CYP is still unclear. ${ }^{1}$ The monooxygenation reaction mechanism by CYP has been investigated on the basis of the idea that the reaction consists of two sequential processes: generation of a radical species $[\mathrm{FeO}]^{3+}$ (compound I) [first step] and monooxygenation of the substrate [second step] (Scheme 2). Hence, the resting state of heme was changed into compound I, i.e., the distance between a heme Fe atom and an oxygen atom at the distal side of heme shrank from $2.06 \AA$ to $1.73 \AA^{34}$ Then, CBZ was docked in the active site of CYP3A4 manually, forming a hydrogen bond between the nitrogen atom of the carbamoyl group of CBZ and the carbonyl oxygen atom of Phe304 with its epoxidation site (C10-C11 double bond) interacting with the oxygen atom of compound I.

5.1.2. Computational details. The computational program used for $M M$ calculations was AMBER $6 .{ }^{49}$ Parm94.dat was utilized as the force field parameter file, whereas the all-atom force field parameter file in AMBER $4.1^{50}$ was utilized for heme.

Point charges on compound I and CBZ for the MM calculation were determined using the RESP module ${ }^{51,52}$ included in the AMBER 6 program package. The electrostatic potential (ESP) at the points selected according to the Merz-Shigh-Kollman scheme ${ }^{53}$ for use in the RESP module was calculated at the HF/6-31G** level of theory. The compound I model for the ESP and RESP calculations was constructed by extracting Asn441, compound I-bound Cys442 and Ile443 from the model described in section 5.1.1 and by replacing Asn441 and Ile443 with an acetyl group and a $\mathrm{NHCH}_{3}$ group, respectively. The $\mathrm{CBZ}$ model for the ESP and RESP calculations was obtained by geometry optimization at the HF/6-31G** 
level. The spin multiplicities were doublet for compound $\mathrm{I}^{34}$ and singlet for CBZ. The total atomic charges for both structures were 0 e. The computational program used for the ESP and optimization calculations was Gaussian $98 .^{32}$ For point charges on other residues, the standard AMBER residue database was utilized.

To construct the model for the MM calculation, about 6,000 TIP3P water molecules ${ }^{54}$ were generated around the CYP3A4-CBZ complex, as described in the previous section, by using solvateShell command of the xaLEaP module included in the AMBER 6 program package. ${ }^{49}$ The thickness of the layer of water molecules was $11 \AA$. Then the whole system except for compound I-bound Cys442, acetyl group and $\mathrm{NHCH}_{3}$ group was fully energy-minimized by the steepest descent method ( 6,000 steps) followed by the conjugate gradient method $(3,000$ steps) of the sander_classic module. Judging from the potential energy of the whole system, the model structure was confirmed to be completely minimized under the calculation steps shown above. In the energy-minimization process, the cutoff distance was $12 \AA$. The

SHAKE constraint, ${ }^{55}$ where all of the bonds are kept at equilibrium distances, was not used. The results are shown in Fig. 1.

5.2. Quantum mechanics calculation using the DFT method. Using the CYP3A4-CBZ complex structure obtained by the above-mentioned method, the process of epoxidation by CYP3A4 was investigated in detail by means of the DFT method.

5.2.1. Construction of models for calculation. Phe304, Ala305, compound I-bound Cys442 and CBZ, which are thought to be directly involved in the epoxidation process, were extracted to construct the models for the DFT study. CBZ is a substrate and interacts with the peptide bond between Phe304 and Ala305 (Fig. 1). Compound I is necessary for the reaction because it has an oxygen atom involving in the monooxygenation reaction. The thiolate anion of Cys442 is the fifth ligand of heme. The atoms shown by balls in Fig. 1 were further 
extracted from Phe304, Ala305 and Cys442, and nitrogen and $\mathrm{C}_{\beta}$ atoms of Phe304, carbonyl carbon and $\mathrm{C}_{\beta}$ atoms of $\mathrm{Ala305}$, and $\mathrm{C}_{\alpha}$ atom of Cys442 shown by green balls in Fig. 1 were all replaced with hydrogen atoms. The protoporphyrin IX part of heme was changed into porphine. The number of atoms is $85\left[\mathrm{H}_{34} \mathrm{C}_{39} \mathrm{~N}_{7} \mathrm{O}_{3} \mathrm{SFe}\right]$ and the total atomic charge is $0 \mathrm{e}$. The constructed models are shown in Figs. 3, 5, 7, 8, 11 and 12 and in Figs. S2 and S3 in SUPPLEMENTARY MATERIAL.

5.2.2. Computational details. The electronic structures of the model compounds were solved by using the DFT method. The basis set used was $3-21 \mathrm{G}^{* *}$. The exchange functional was Becke's three-parameter functional, ${ }^{56}$ and the correlation functional was Lee-Yang-Parr's formula. $^{57}$

Results of studies on the epoxidation mechanism by compound I have been published. Gross et al. ${ }^{58}$ proposed a classification of the intermediates in the epoxidation of alkenes into four species; i.e., metallacycle, ${ }^{59,60}$ charge-transfer, ${ }^{61}$ electron-transfer ${ }^{62}$ and radical complexes. $^{58,63}$ de Visser et al. argued that the radical complex is most compatible with experimental results and elucidated a mechanism of the epoxidation of ethane via a radical complex by DFT calculations. ${ }^{38}$ The results of our study also supported the epoxidation mechanism via a radical complex, which consists of two sequential processes: (1) single C-O bond formation (radical complex formation) and (2) ring closure to produce the epoxide. The structures at the minima on the potential energy hypersurface were obtained in the DFT calculation. The atoms marked by asterisks (6 atoms) in Fig. 3(D1) were fixed in the structure obtained by the MM calculation (Fig. 1). The other atoms were allowed to move. Potential energy profiles were obtained by changing the distances shown in horizontal axes of Figs. 2, 4, 6 and 10 and of Figs. S1 in SUPPLEMENTARY MATERIAL. The computational program used was Gaussian $98 .^{32}$ 
The mechanism of monooxygenation from compound I has been analyzed in two spin states: doublet and quartet states. In our previous work, ${ }^{34}$ the doublet state was adopted to investigate the mechanism because the potential energy of the low-spin state $\left({ }^{2} \mathrm{~A}_{2 \mathrm{u}}\right)$ structure was $2.4 \mathrm{kcal} / \mathrm{mol}$ lower than that of the high-spin state $\left({ }^{4} \mathrm{~A}_{2 \mathrm{u}}\right)$. This result agrees with the results obtained by Harris et al. $(3 \mathrm{kcal} / \mathrm{mol}) .{ }^{64}$ Yoshizawa et al. investigated the alkane hydroxylation by compound I at both the doublet and quartet states and also showed that the potential energy of compound I in the doublet state was more stable than that of the compound in the quartet state, although the energy difference was very small $(0.1 \mathrm{kcal} / \mathrm{mol}) .{ }^{65,66}$ On the other hand, the results obtained by Filatov et al. indicated that the doublet state was slightly higher in energy than the quartet state. $^{40}$ They proposed a two-state reactivity (TSR) mechanism; i.e., in the hydroxylation of the substrate by P-450 ferryl complex, a spin-state crossing occurs between the high-spin (quartet) and the low-spin (doublet) states, and a lowspin state structure is produced. ${ }^{35-47}$ In this study, calculations were performed at both spin states to compare the potential energy and the structure differences between the two spin states.

Since the active site in a protein is not isolated but is enclosed by many molecules or residues, inclusion of the effect of the dielectric constant seems important when attempting to reproduce the environment inside a protein through theoretical approaches. In our previous work, ${ }^{34}$ geometry optimizations were performed for the stable and transition states on the reaction path, setting the dielectric constant of the surroundings to $20 .^{67,68}$ The SelfConsistent Reaction Field (SCRF) method using the Polarized Continuum Model (PCM) of Tomasi and coworkers ${ }^{69-78}$ was used for computations. However, no significant differences were observed between the results obtained in vacuum and those obtained using a dielectric constant of 20. Hence, SCRF method was not adopted in this study. 


\section{ACKNOWLEDGMENT}

This work was supported by Grant-in-Aid for Scientific Research (C) (KAKENHI (19590137)). A part of this work was supported by Japan Science and Technology Agency and "THE FUJISAWA FOUNDATION". The computations were carried out by Fujitsu VPP5000 computer at the Computer Center of the Institute for Molecular Science and DRIA system at Graduate School of Pharmaceutical Sciences, Chiba University 


\section{REFERENCES AND NOTES}

1. Sono, M.; Roach, M. P.; Coulter, E. D.; Dawson, J. H. Chem. Rev. 1996, 96, 2841.

2. Woggon, W.-D. Top. Curr. Chem. 1997, 184, 39.

3. Estabrook, R. W.; Hildebrandt, A. G.; Baron, J.; Netter, K. J.; Leibman, K. Biochem.

Biophys. Res. Commun. 1971, 42, 132.

4. Denisov, I. G.; Makris, T. M.; Sligar, S. G.; Schlichting, I. Chem. Rev. 2005, 105, 2253.

5. Shaik, S.; Kumar, D.; Visser, S. P. d.; Altun, A.; Thiel, W. Chem. Rev. 2005, 105, 2279.

6. Poulos, T. L.; Finzel, B. C.; Howard, A. J. J. Mol. Biol. 1987, 195, 687.

7. Ravichandran, K. G.; Boddupalli, S. S.; Hasermann, C. A.; Peterson, J. A.; Deisenhofer, J. Science 1993, 261, 731.

8. Hasemann, C. A.; Ravichandran, K. G.; Peterson, J. A.; Deisenhofer, J. J. Mol. Biol. 1994, $236,1169$.

9. Cupp-Vickery, J. R.; Poulos, T. L. Nat. Struct. Mol. Biol. 1995, 2, 144.

10. Podust, L. M.; Poulos, T. L.; Waterman, M. R. Proc. Natl. Acad. Sci. USA 2001, 98, 3068.

11. Rowland, P.; Blaney, F. E.; Smyth, M. G.; Jones, J. J.; Leydon, V. R.; Oxbrow, A. K.;

Lewis, C. J.; Tennant, M. G.; Modi, S.; Eggleston, D. S.; Chenery, R. J.; Bridges, A. M. J.

Biol. Chem. 2006, 281, 7614.

12. Williams, P. A.; Cosme, J.; Sridhar, V.; Johnson, E. F.; McRee, D. E. Mol. Cell 2000, 5, 121.

13. Williams, P. A.; Cosme, J.; Ward, A.; Angove, H. C.; Vinkovic, D. M.; Jhoti, H. Nature 2003, $424,464$.

14. Schoch, G. A.; Yano, J. K.; Wester, M. R.; Griffin, K. J.; Stout, C. D.; Johnson, E. F. J. Biol. Chem. 2004, 279, 9497.

15. Wester, M. R.; Yano, J. K.; Schoch, G. A.; Yang, C.; Griffin, K. J.; Stout, C. D.; Johnson, E. F. J. Biol. Chem. 2004, 279, 35630. 
16. Yano, J. K.; Wester, M. R.; Schoch, G. A.; Griffin, K. J.; Stout, C. D.; Johnson, E. F. J. Biol. Chem. 2004, 279, 38091.

17. Scott, E. E.; He, Y. A.; Wester, M. R.; White, M. A.; Chin, C. C.; Halpert, J. R.; Johnson, E. F.; Stout, C. D. Proc. Natl. Acad. Sci. USA 2003, 100, 13196.

18. Yano, J. K.; Hsu, M.-H.; Griffin, K. J.; Stout, C. D.; Johnson, E. F. Nat. Struct. Mol. Biol. 2005, 12,822 .

19. Williams, P. A.; Cosme, J.; Vinkovic, D. M.; Ward, A.; Angove, H. C.; Day, P. J.;

Vonrhein, C.; Tickle, I. J.; Jhoti, H. Science 2004, 305, 683.

20. Ekroos, M.; Sjogren, T. Proc. Natl. Acad. Sci. U. S. A. 2006, 103, 13682.

21. Sansen, S.; Yano, J. K.; Reynald, R. L.; Schoch, G. A.; Griffin, K. J.; Stout, C. D.;

Johnson, E. F. J. Biol. Chem. 2007, 282, 14348.

22. Smith, B. D.; Sanders, J. L.; Porubsky, P. R.; Lushington, G. H.; Stout, C. D.; Scott, E. E. J. Biol. Chem. 2007, 282, 17306.

23. Bathelt, C.; Schmid, R. D.; Pleiss, J. J. Mol. Model. 2002, 8, 327.

24. Yamamoto, K.; Masuno, H.; Sawada, N.; Sakaki, T.; Inouye, K.; Ishiguro, M.; Yamada, S. J. Steroid Biochem. Mol. Biol. 2004, 89-90, 167.

25. Prosser, D. E.; Guo, Y.; Jia, Z.; Jones, G. Biophys. J. 2006, 90, 3389.

26. Lafite, P.; Andre, F.; Zeldin, D. C.; Dansette, P. M.; Mansuy, D. Biochemistry 2007, 46, 10237.

27. Uttamsingh, V.; Lu, C.; Miwa, G.; Gan, L.-S. Drug Metab. Dispos. 2005, 33, 1723.

28. Torimoto, N.; Ishii, I.; Hata, M.; Nakamura, H.; Imada, H.; Ariyoshi, N.; Ohmori, S.;

Igarashi, T.; Kitada, M. Biochemistry 2003, 42, 15068.

29. Torimoto, N.; Ishii, I.; Hata, M.; Kobayashi, Y.; Nakamura, H.; Ariyoshi, N.; Kitada, M. Biochim. Biophys. Acta, Proteins Proteomics 2007, 1774, 223. 
30. Kerr, B. M.; Thummel, K. E.; Wurden, C. J.; Klein, S. M.; Kroetz, D. L.; Gonzalez, F. J.; Levy, R. H. Biochem. Pharmacol. 1994, 47, 1969.

31. Maggs, J. L.; Pirmohamed, M.; Kitteringham, N. R.; Park, B. K. Drug Metab. Dispos. $1997,25,275$.

32. Frisch, M. J.; Trucks, G. W.; Schlegel, H. B.; Scuseria, G. E.; Robb, M. A.; Cheeseman, J. R.; Zakrzewski, V. G.; Montgomery Jr., J. A.; Stratmann, R. E.; Burant, J. C.; Dapprich, S.; Millam, J. M.; Daniels, A. D.; Kudin, K. N.; Strain, M. C.; Farkas, O.; Tomasi, J.; Barone, V.; Cossi, M.; Cammi, R.; Mennucci, B.; Pomelli, C.; Adamo, C.; Clifford, S.; Ochterski, J.; Petersson, G. A.; Ayala, P. Y.; Cui, Q.; Morokuma, K.; Salvador, P.; Dannenberg, J. J.; Malick, D. K.; Rabuck, A. D.; Raghavachari, K.; Foresman, J. B.; Cioslowski, J.; Ortiz, J. V.; Baboul, A. G.; Stefanov, B. B.; Liu, G.; Liashenko, A.; Piskorz, P.; Komaromi, I.; Gomperts, R.; Martin, R. L.; Fox, D. J.; Keith, T.; Al-Laham, M. A.; Peng, C. Y.; Nanayakkara, A.;

Challacombe, M.; Gill, P. M. W.; Johnson, B.; Chen, W.; Wong, M. W.; Andres, J. L.; Gonzalez, C.; Head-Gordon, M.; Replogle, E. S.; Pople, J. A. Gaussian 98, Revision A.11; Gaussian, Inc.: Pittsburgh PA, 2001.

33. Faigle, J. W.; Feldmann, K. F. In Antiepileptic Drugs; Woodbury, D. M., Ed.; Raven Press: New York, 1982; pp 483-495.

34. Hata, M.; Hirano, Y.; Hoshino, T.; Tsuda, M. J. Am. Chem. Soc. 2001, 123, 6410.

35. Shaik, S.; Filatov, M.; Schröder, D.; Schwarz, H. Chem. Eur. J. 1998, 4, 193.

36. Harris, N.; Cohen, S.; Filatov, M.; Ogliaro, F.; Shaik, S. Angew. Chem. Int. Ed. 2000, 39, 2003.

37. Ogliaro, F.; Harris, N.; Cohen, S.; Filatov, M.; de Visser, S. P.; Shaik, S. J. Am. Chem. Soc. 2000, 122, 8977.

38. de Visser, S. P.; Ogliaro, F.; Harris, N.; Shaik, S. J. Am. Chem. Soc. 2001, 123, 3037. 39. de Visser, S. P.; Ogliaro, F.; Sharma, P. K.; Shaik, S. J. Am. Chem. Soc. 2002, 124, 11809. 40. Filatov, M.; Harris, N.; Shaik, S. J. Chem. Soc., Perkin Trans. 2 1999, 1999, 399. 
41. de Visser, S. P.; Ogliaro, F.; Sharma, P. K.; Shaik, S. Angew. Chem. Int. Ed. 2002, 41, 1947.

42. Sharma, P. K.; de Visser, S. P.; Ogliaro, F.; Shaik, S. J. Am. Chem. Soc. 2003, 125, 2291. 43. Kumar, D.; de Visser, S. P.; Shaik, S. J. Am. Chem. Soc. 2003, 125, 13024.

44. Kumar, D.; de Visser, S. P.; Sharma, P. K.; Cohen, S.; Shaik, S. J. Am. Chem. Soc. 2004, $126,1907$.

45. Schöneboom, J. C.; Cohen, S.; Lin, H.; Shaik, S.; Thiel, W. J. Am. Chem. Soc. 2004, 126, 4017.

46. Kumar, D.; de Visser, S. P.; Sharma, P. K.; Hirao, H.; Shaik, S. Biochemistry 2005, 44, 8148.

47. Hirao, H.; Kumar, D.; Thiel, W.; Shaik, S. J. Am. Chem. Soc. 2005, 127, 13007.

48. Domanski, T. L.; He, Y.-A.; Harlow, G. R.; Halpert, J. R. J. Pharmacol. Exp. Ther. 2000, $293,585$.

49. Case, D. A.; Pearlman, D. A.; Caldwell, J. W.; Cheatham III, T. E.; Ross, W. S.;

Simmerling, C. L.; Darden, T. A.; Merz, K. M.; Stanton, R. V.; Cheng, A. L.; Vincent, J. J.;

Crowley, M.; Tsui, V.; Radmer, R. J.; Duan, Y.; Pitera, J.; Massova, I.; Seibel, G. L.; Singh, U. C.; Weiner, P. K.; Kollman, P. A. AMBER 6; University of California: San Francisco, 1999.

50. Pearlman, D. A.; Case, D. A.; Caldwell, J. W.; Ross, W. S.; Cheatham III, T. E.;

Ferguson, D. M.; Seibel, G. L.; Singh, U. C.; Weiner, P. K.; Kollman, P. A. AMBER 4.1; University of California: San Francisco, 1995.

51. Bayly, C. I.; Cieplak, P.; Cornell, W.; Kollman, P. A. J. Phys. Chem. 1993, 97, 10269. 52. Cornell, W. D.; Cieplak, P.; Bayly, C. I.; Kollmann, P. A. J. Am. Chem. Soc. 1993, 115, 9620.

53. Singh, U. C.; Kollman, P. A. J. Comput. Chem. 1984, 5, 129. 
54. Jorgensen, W. L.; Chandrasekhar, J.; Madura, J. D.; Impey, R. W.; Klein, M. L. J. Chem. Phys. 1983, 79, 926.

55. Ryckaert, J. P.; Ciccotti, G.; Berendsen, H. J. C. J. Comput. Phys. 1977, 23, 327.

56. Becke, A. D. J. Chem. Phys. 1993, 98, 5648.

57. Lee, C.; Yang, W.; Parr, R. G. Phys. Rev. B 1988, 37, 785.

58. Gross, Z.; Nimri, S.; Barzilay, C. M.; Simkhovich, L. J. Biol. Inorg. Chem 1997, 2, 492.

59. Groves, J. T.; Avaria-Neisser, G. E.; Fish, K. M.; Imachi, M.; Kuczkowski, R. L. J. Am.

Chem. Soc. 1986, 108, 3837.

60. Collman, J. P.; Brauman, J. I.; Hampton, P. D.; Tanaka, H.; Bohle, D. S.; Hembre, R. T. J. Am. Chem. Soc. 1990, 112, 7980.

61. Arasasingham, R. D.; He, G. X.; Bruice, T. C. J. Am. Chem. Soc. 1993, 115, 7985.

62. Traylor, T. G. Pure Appl. Chem. 1991, 63, 265.

63. Rietjens, I. M. C. M.; Osman, A. M.; Veeger, C.; Zakharieva, O.; Antony, J.; Grodzicki, M.; Trautwein, A. X. J. Biol. Inorg. Chem 1996, 1, 372.

64. Harris, D. L.; Loew, G. H. J. Am. Chem. Soc. 1998, $120,8941$.

65. Yoshizawa, K.; Kagawa, Y.; Shiota, Y. J. Phys. Chem. B 2000, 105, 12365.

66. Yoshizawa, K.; Kamachi, T.; Shiota, Y. J. Am. Chem. Soc. 2001, 123, 9806.

67. Antosiewicz, J.; McCammon, J. A.; Gilson, M. K. Biochemistry 1996, 35, 7819.

68. Sham, Y. Y.; Muegge, I.; Warshel, A. Biophys. J. 1998, 74, 1744.

69. Miertus, S.; Scrocco, E.; Tomasi, J. Chem. Phys. 1981, 55, 117.

70. Miertus, S.; Tomasi, J. Chem. Phys. 1982, 65, 239.

71. Cossi, M.; Barone, V.; Cammi, R.; Tomasi, J. Chem. Phys. Lett. 1996, 255, 327.

72. Cancès, E.; Mennucci, B.; Tomasi, J. J. Chem. Phys. 1997, 107, 3032.

73. Barone, V.; Cossi, M.; Tomasi, J. J. Chem. Phys. 1997, 107, 3210.

74. Cancès, E.; Mennucci, B. J. Chem. Phys. 1998, 109, 249. 
75. Cancès, E.; Mennucci, B.; Tomasi, J. J. Chem. Phys. 1998, 109, 260.

76. Cossi, M.; Barone, V.; Mennucci, B.; Tomasi, J. Chem. Phys. Lett. 1998, 286, 253.

77. Barone, V.; Cossi, M.; Tomasi, J. J. Comput. Chem. 1998, 19, 404.

78. Barone, V.; Cossi, M. J. Phys. Chem. A 1998, 102, 1995. 


\section{TABLES}

Table 1. Energy difference between 10,11-epoxide and hydroxides of CBZ.

\begin{tabular}{lcc}
\hline Product & $\begin{array}{c}\text { Oxidation } \\
\text { Site }^{\mathrm{a}}\end{array}$ & $\begin{array}{c}\text { Relative Energy } \\
(\mathrm{kcal} / \mathrm{mol})^{\mathrm{b}}\end{array}$ \\
\hline Epoxide & 10,11 & 0.0 \\
Hydroxide & 1 & -18.56 \\
& 2 & -18.81 \\
& 3 & -18.74 \\
& 4 & -21.28 \\
& 6 & -24.43 \\
& 7 & -18.87 \\
8 & -18.62 \\
9 & -18.72 \\
\hline
\end{tabular}

${ }^{\mathrm{a}}$ See Scheme 1.

${ }^{b}$ Those energies were obtained by geometry optimization at the B3LYP/6-31G** level. 
Table 2. Changes in inter-atomic distances (in $\AA$ ) upon epoxidation of CBZ by CYP3A4 in the doublet state.

\begin{tabular}{llllll}
\hline & (D1) & (D2) & (D3) & (D4) & (D5) \\
\hline C10--O1 & 2.89 & 2.10 & 1.51 & 1.47 & 1.55 \\
C11--O1 & 3.40 & 2.78 & 2.46 & 2.11 & 1.57 \\
Fe--O1 & 1.61 & 1.70 & 1.82 & 1.87 & 2.25 \\
C10--C11 & 1.35 & 1.39 & 1.49 & 1.45 & 1.48 \\
NH--O & 2.83 & 2.76 & 2.78 & 2.78 & 2.78 \\
H1--O & 3.03 & 3.04 & 3.07 & 3.08 & 3.04 \\
H2--O & 1.97 & 1.86 & 1.88 & 1.87 & 1.90 \\
\hline
\end{tabular}


Table 3. Changes in spin density distribution ${ }^{\mathrm{a}}$ upon epoxidation of CBZ by CYP3A4 in the doublet state.

\begin{tabular}{lrrrrr}
\hline & (D1) & (D2) & (D3) & (D4) & (D5) \\
\hline O1 & 0.62 & -0.08 & 0.14 & 0.16 & -0.00 \\
Fe & 1.43 & 1.87 & 2.10 & 1.92 & 1.09 \\
Cys442(S-Me) & -0.88 & -0.20 & -0.22 & -0.20 & 0.02 \\
Porphine & -0.17 & -0.15 & -0.14 & -0.16 & -0.10 \\
CBZ & -0.01 & -0.44 & -0.88 & -0.72 & 0.00 \\
(C10) & -0.00 & 0.08 & 0.06 & 0.05 & 0.00 \\
$\quad$ (C11) & -0.00 & -0.39 & -0.72 & -0.63 & -0.00 \\
Phe304-Ala305 & 0.00 & 0.00 & 0.00 & 0.00 & 0.00 \\
\hline
\end{tabular}

${ }^{a}$ Values were obtained by Mulliken population analysis. 
Table 4. Changes in inter-atomic distances (in $\AA$ ) upon epoxidation of CBZ by CYP3A4 in the quartet state.

\begin{tabular}{lccccc}
\hline & $(\mathrm{Q} 1)$ & $(\mathrm{Q} 2)$ & $(\mathrm{Q} 3)$ & $(\mathrm{Q} 4)$ & $(\mathrm{Q} 5)$ \\
\hline $\mathrm{C} 10--\mathrm{O} 1$ & 2.88 & 1.98 & 1.50 & 1.48 & 1.53 \\
$\mathrm{C} 11--\mathrm{O} 1$ & 3.40 & 2.71 & 2.47 & 2.10 & 1.53 \\
Fe--O1 & 1.61 & 1.67 & 1.84 & 2.12 & 2.94 \\
$\mathrm{C} 10--\mathrm{C} 11$ & 1.35 & 1.39 & 1.50 & 1.47 & 1.48 \\
$\mathrm{NH}--\mathrm{O}$ & 2.83 & 2.77 & 2.77 & 2.76 & 2.77 \\
$\mathrm{H} 1--\mathrm{O}$ & 3.03 & 3.07 & 3.06 & 3.06 & 3.10 \\
$\mathrm{H} 2--\mathrm{O}$ & 1.97 & 1.87 & 1.88 & 1.84 & 1.84 \\
\hline
\end{tabular}


Table 5. Changes in spin density distribution ${ }^{\mathrm{a}}$ upon epoxidation of CBZ by CYP3A4 in the quartet state.

\begin{tabular}{lrrrrr}
\hline & $(\mathrm{Q})$ & $(\mathrm{Q} 2)$ & $(\mathrm{Q} 3)$ & $(\mathrm{Q} 4)$ & $(\mathrm{Q} 5)$ \\
\hline $\mathrm{O} 1$ & 0.65 & 0.57 & 0.23 & 0.08 & 0.01 \\
$\mathrm{Fe}$ & 1.38 & 1.38 & 2.19 & 1.43 & 2.69 \\
Cys442(S-Me) & 0.87 & 0.70 & -0.24 & 0.58 & 0.36 \\
Porphine & 0.10 & 0.04 & -0.13 & 0.22 & -0.06 \\
CBZ & 0.01 & 0.31 & 0.95 & 0.68 & -0.00 \\
(C10) & 0.00 & -0.08 & -0.05 & -0.04 & -0.00 \\
(C11) & 0.01 & 0.29 & 0.75 & 0.56 & -0.00 \\
Phe304-Ala305 & 0.00 & 0.00 & 0.00 & 0.00 & 0.00 \\
\hline
\end{tabular}

${ }^{\mathrm{a}}$ Values were obtained by Mulliken population analysis. 
Table 6. Changes in inter-atomic distances (in $\AA$ ) upon one-step epoxidation of CBZ by CYP3A4 in the (a) doublet and (b) quartet states.

(a)

\begin{tabular}{llll}
\hline & (D6) & (D7) & (D8) \\
\hline C10--O1 & 2.90 & 2.02 & 1.55 \\
C11--O1 & 2.88 & 2.02 & 1.56 \\
Fe--O1 & 1.61 & 1.78 & 2.37 \\
C10--C11 & 1.35 & 1.40 & 1.48 \\
NH--O & 2.84 & 2.73 & 2.73 \\
H1--O & 3.14 & 2.97 & 2.90 \\
H2--O & 1.94 & 1.87 & 1.91 \\
\hline
\end{tabular}

(b)

\begin{tabular}{llll} 
& $(\mathrm{Q} 6)$ & $(\mathrm{Q} 7)$ & $(\mathrm{Q} 8)$ \\
\hline C10--O1 & 3.00 & 2.03 & 1.52 \\
C11--O1 & 2.98 & 2.03 & 1.53 \\
Fe--O1 & 1.61 & 1.75 & 3.16 \\
C10--C11 & 1.35 & 1.39 & 1.49 \\
NH--O & 2.84 & 2.76 & 2.75 \\
H1--O & 3.17 & 3.09 & 2.93 \\
H2--O & 1.91 & 1.84 & 1.91 \\
\hline
\end{tabular}


Table 7. Changes in inter-atomic distances (in $\AA$ ) of the first elementary step for the epoxide intermediate formation in the hydroxylation of (a) C9 and (b) C8 of CBZ by CYP3A4 in the doublet state.

\begin{tabular}{llll}
\hline & & & \\
\hline & (D9) & (D10) & (D11) \\
\hline C9--O1 & 2.80 & 1.86 & 1.50 \\
Fe--O1 & 1.61 & 1.71 & 1.84 \\
NH--O & 2.78 & 2.74 & 2.73 \\
H1--O & 3.16 & 3.19 & 3.17 \\
H2--O & 1.85 & 1.78 & 1.78 \\
\hline
\end{tabular}

(b)

\begin{tabular}{lccc}
\hline & (D12) & (D13) & (D14) \\
\hline C8--O1 & 3.08 & 1.88 & 1.50 \\
Fe--O1 & 1.61 & 1.70 & 1.81 \\
NH--O & 2.87 & 2.74 & 2.73 \\
H1--O & 3.30 & 3.28 & 3.26 \\
H2--O & 1.89 & 1.74 & 1.74 \\
\hline
\end{tabular}




\section{LEGENDS}

Figure 1. Active site of the enzyme-substrate (CBZ) complex structure obtained by MM calculations. Numerals are inter-atomic distances in $\AA$.

Figure 2. Potential energy changes in epoxidation of CBZ by CYP3A4 in the doublet state. (a) first step and (b) second step.

Figure 3. Structural changes in epoxidation of CBZ by CYP3A4 in the doublet state.

Figure 4. Potential energy changes in epoxidation of CBZ by CYP3A4 in the quartet state. (a) first step and (b) second step.

Figure 5. Structural changes in epoxidation of CBZ by CYP3A4 in the quartet state.

Figure 6. Potential energy changes upon one-step epoxidation of CBZ by CYP3A4 in the (a) doublet and (b) quartet states.

Figure 7. Structural changes upon one-step epoxidation of CBZ by CYP3A4 in the doublet state.

Figure 8. Structural changes upon one-step epoxidation of CBZ by CYP3A4 in the quartet state.

Figure 9. Potential energy diagram on the epoxidation of CBZ by CYP3A4. Numerals in parentheses are relative energies calculated by the DFT method (B3LYP/6-31G**). 
Figure 10. Potential energy changes in the first elementary step for the epoxide intermediate formation in the hydroxylation of (a) C9 and (b) C8 of CBZ by CYP3A4 in the doublet state.

Figure 11. Structural changes in the first elementary step for the epoxide intermediate formation in the hydroxylation of C9 of CBZ by CYP3A4 in the doublet state.

Figure 12. Structural changes in the first elementary step for the epoxide intermediate formation in the hydroxylation of $\mathrm{C} 8$ of $\mathrm{CBZ}$ by CYP3A4 in the doublet state.

Scheme 1. Metabolic pathway of carbamazepine (CBZ) by CYP3A4. Numbering of atoms of CBZ is according to Ref. 31.

Scheme 2. Substrate epoxidation by cytochrome P450. 
Figures

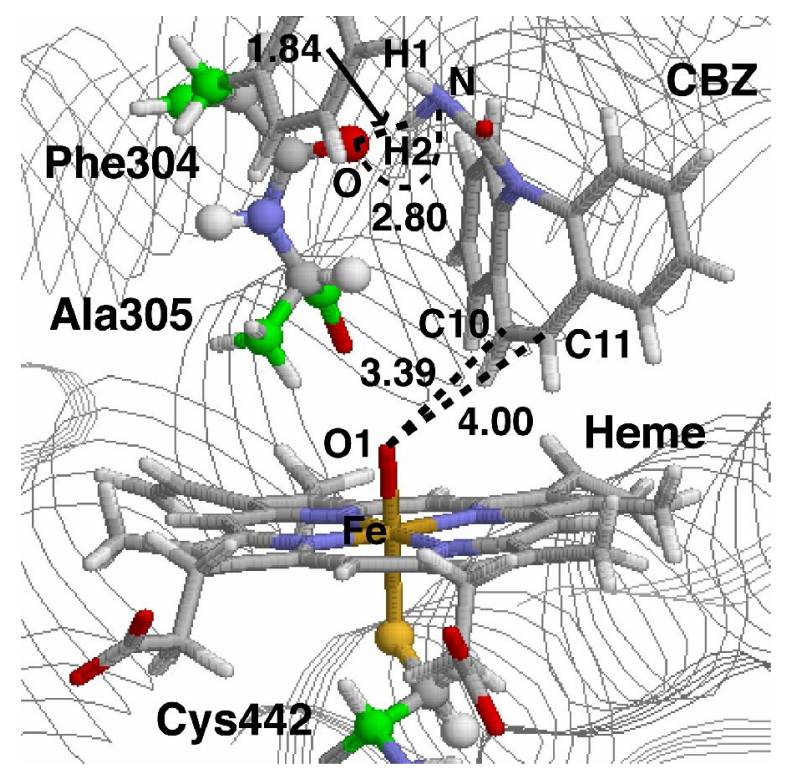

Figure 1 
(a)

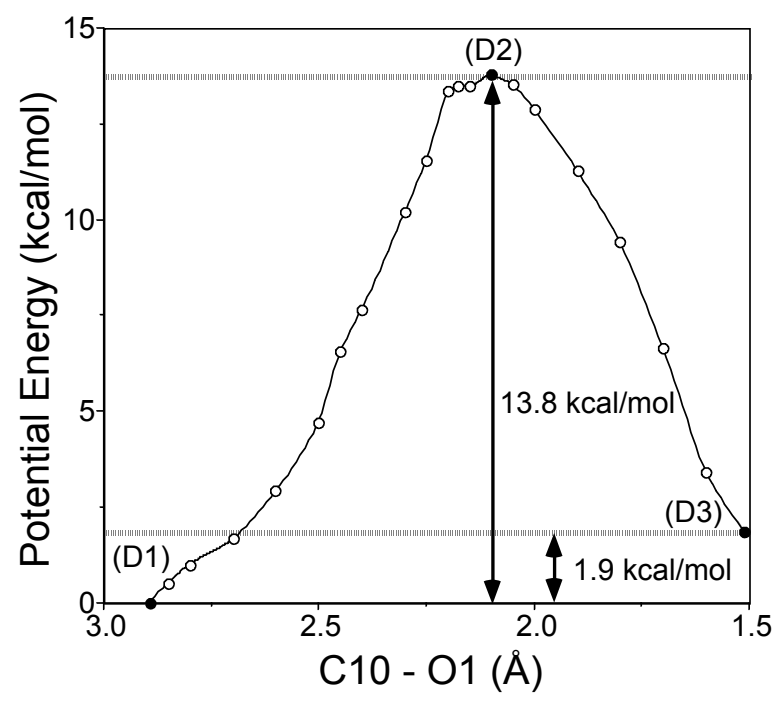

(b)

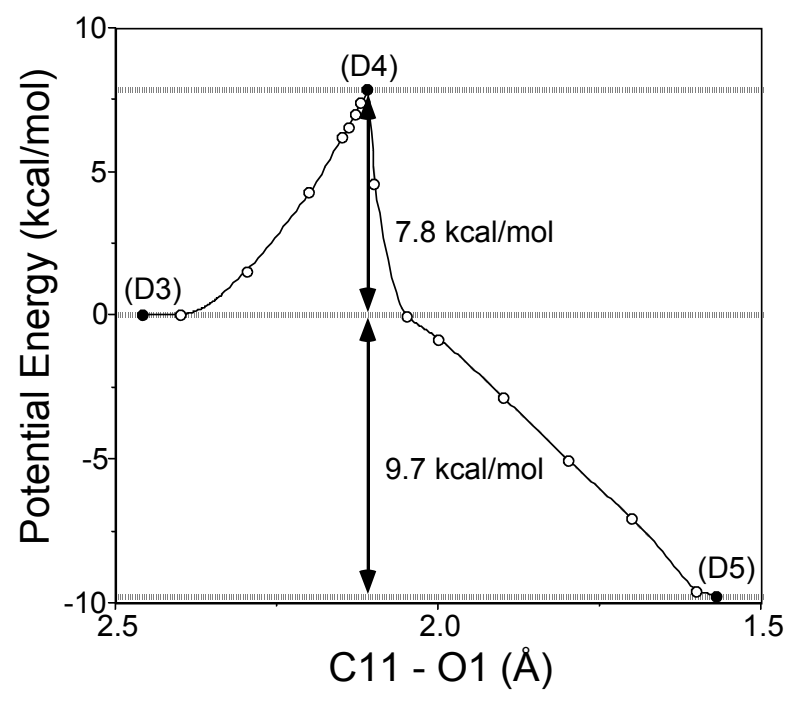

Figure 2 
(D1)

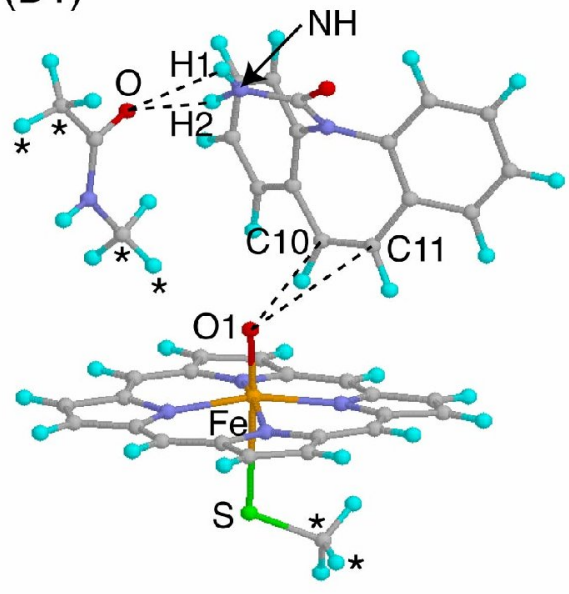

(D3)

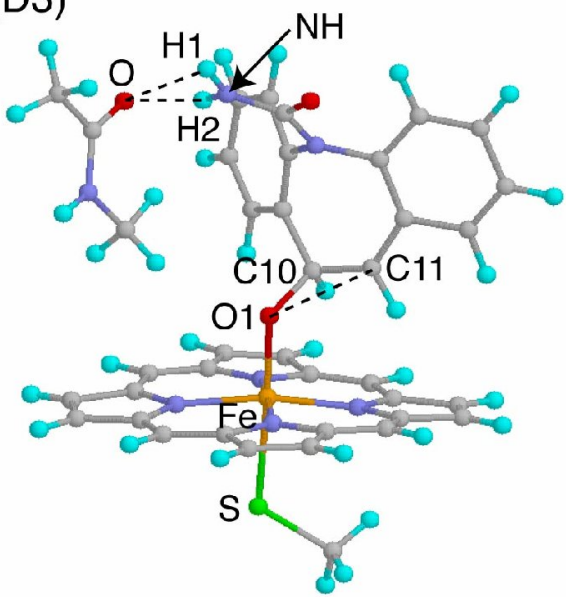

(D2)
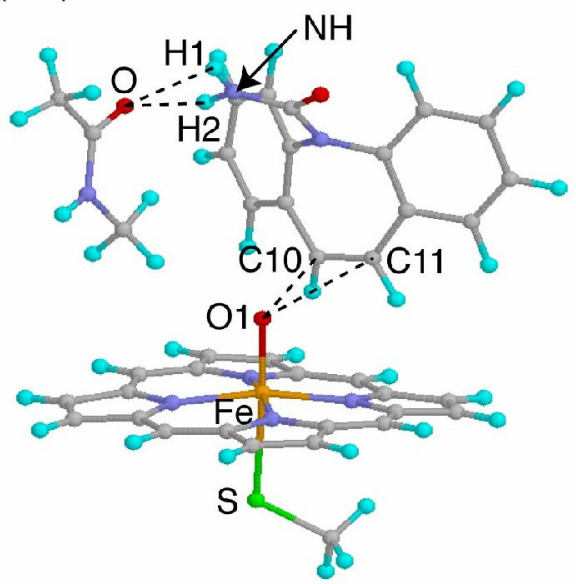

(D4)

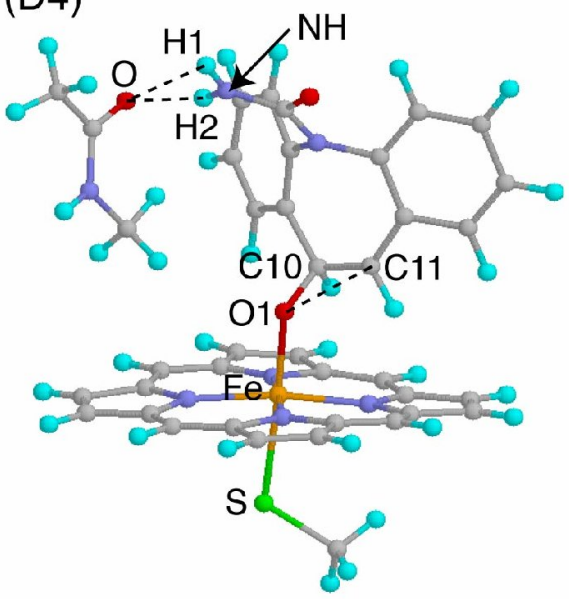

(D5)

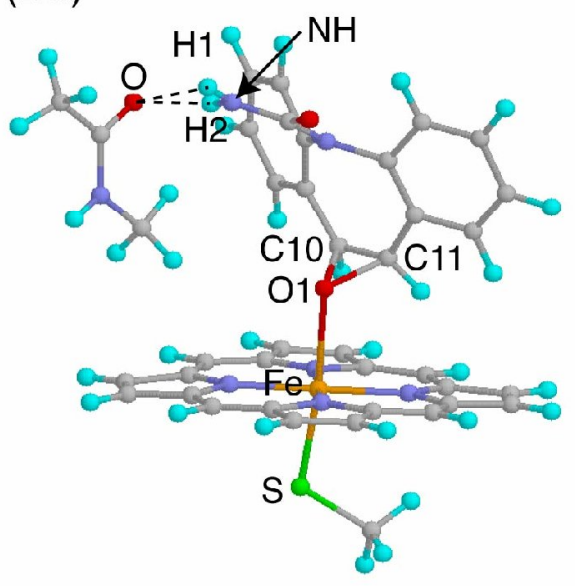

Figure 3 
(a)

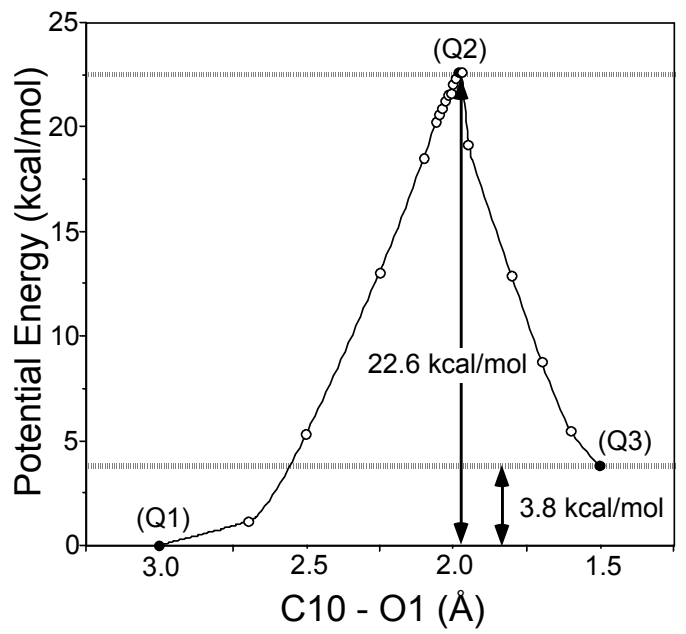

(b)

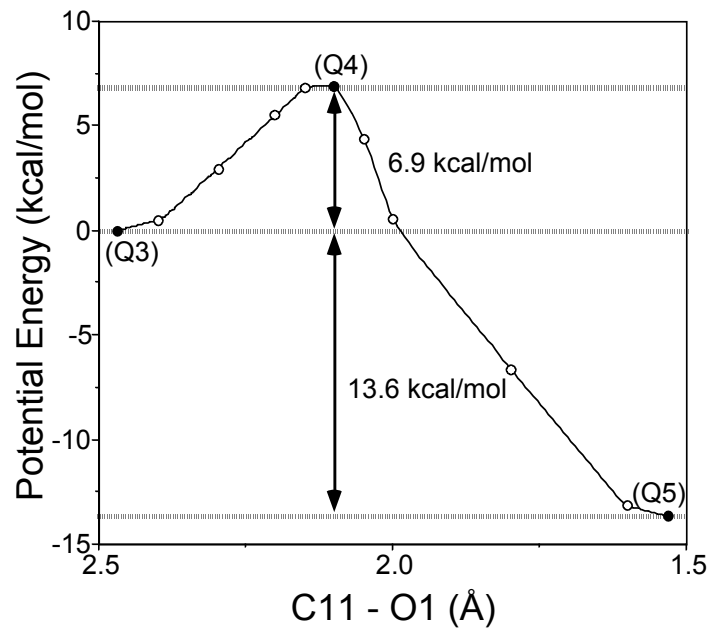

Figure 4 
(Q1)

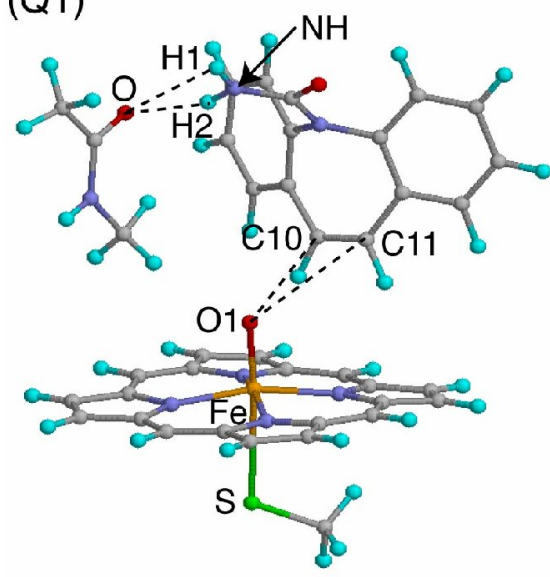

(Q3)

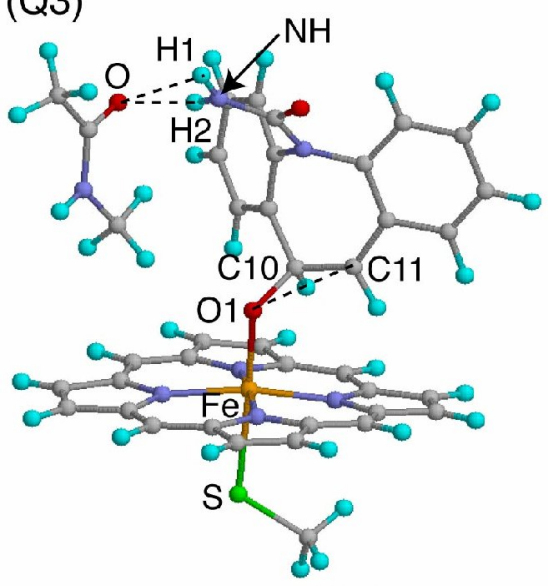

(Q2)
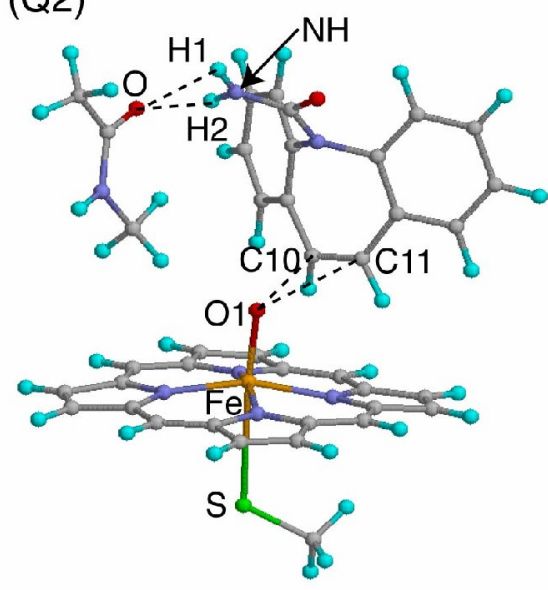

(Q4)

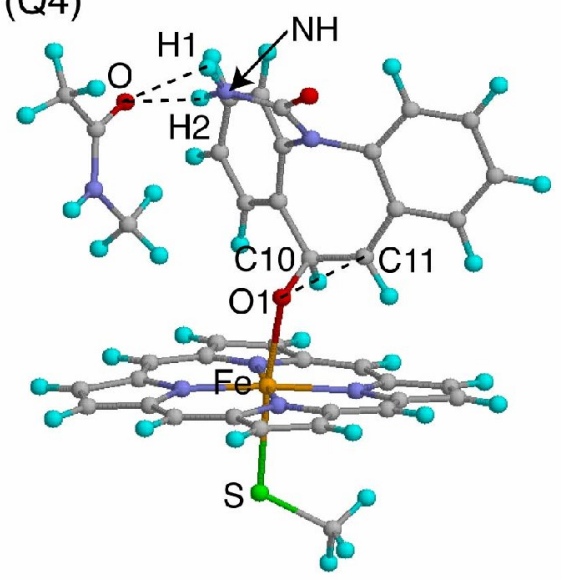

(Q5)

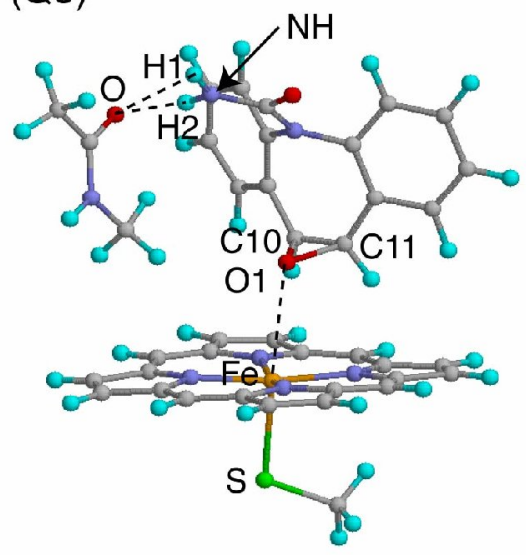

Figure 5 
(a)

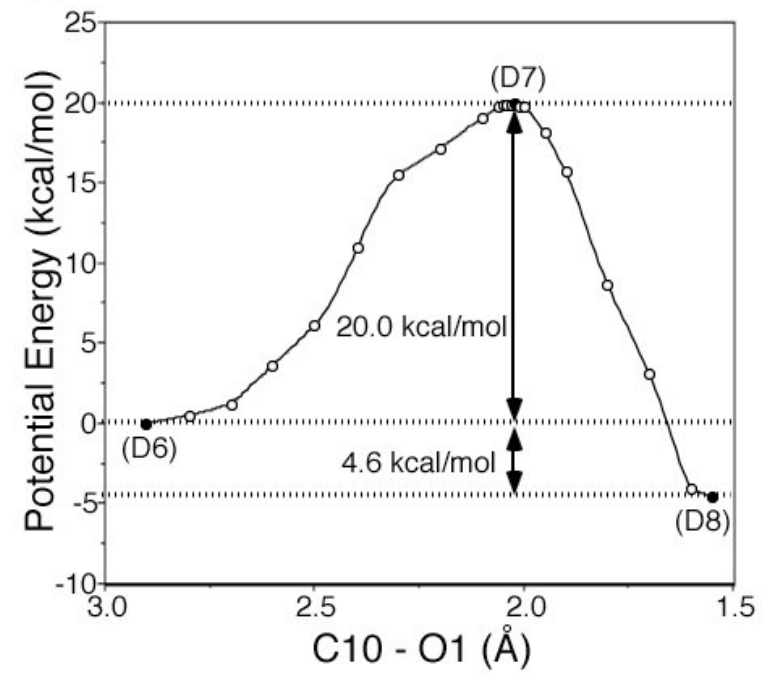

(b)

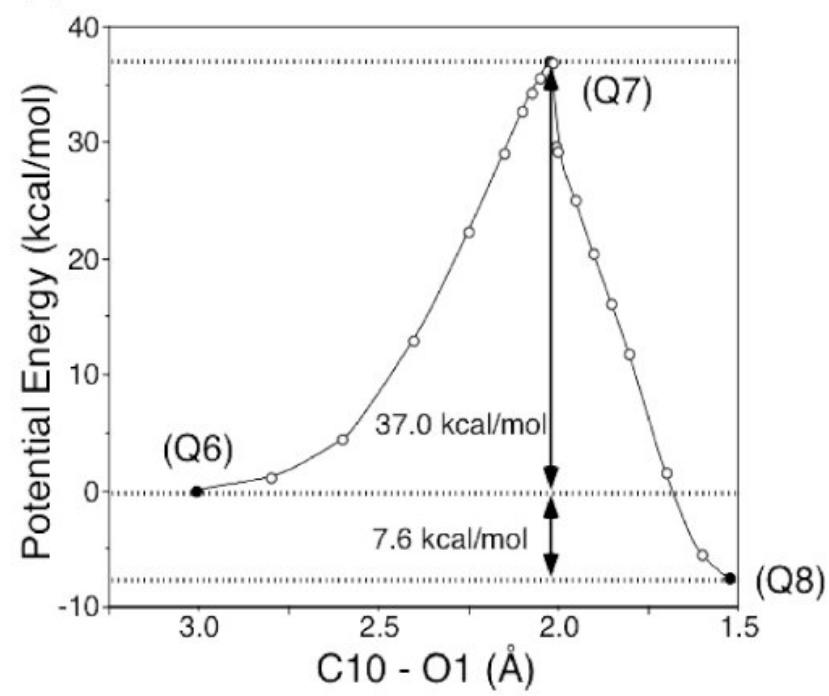

Figure 6 
(D6)

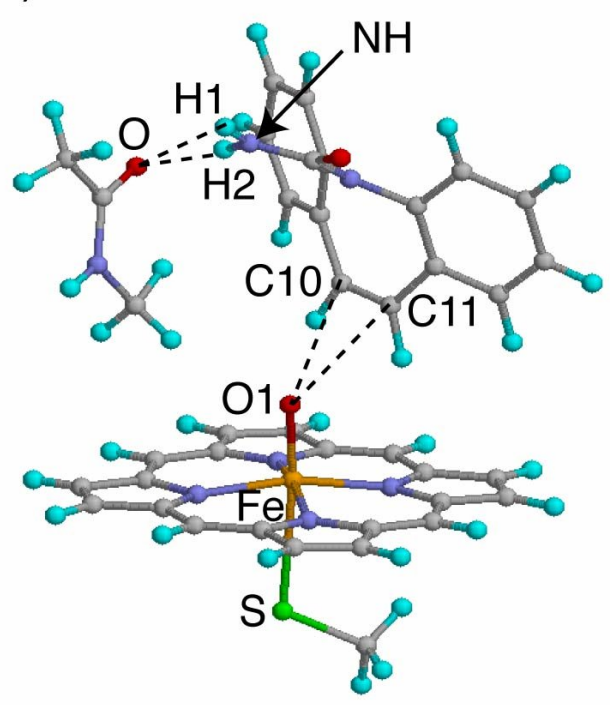

(D7)

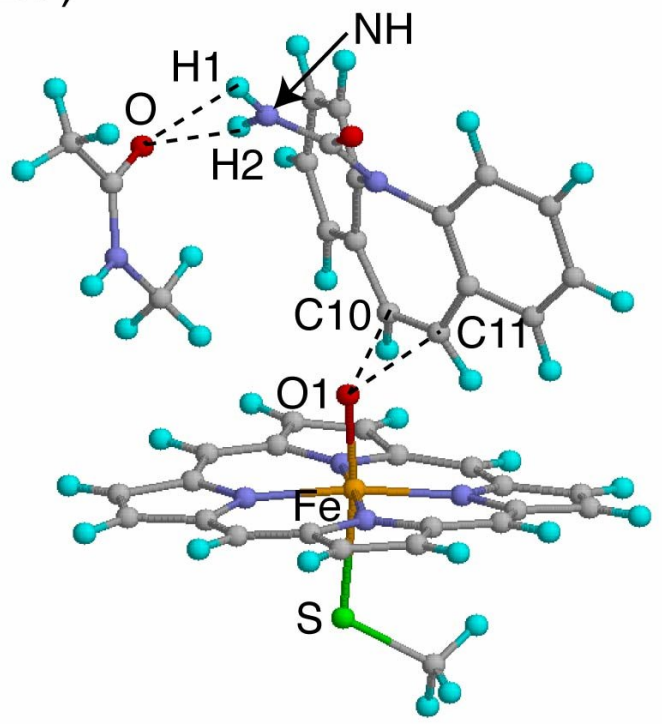

(D8)

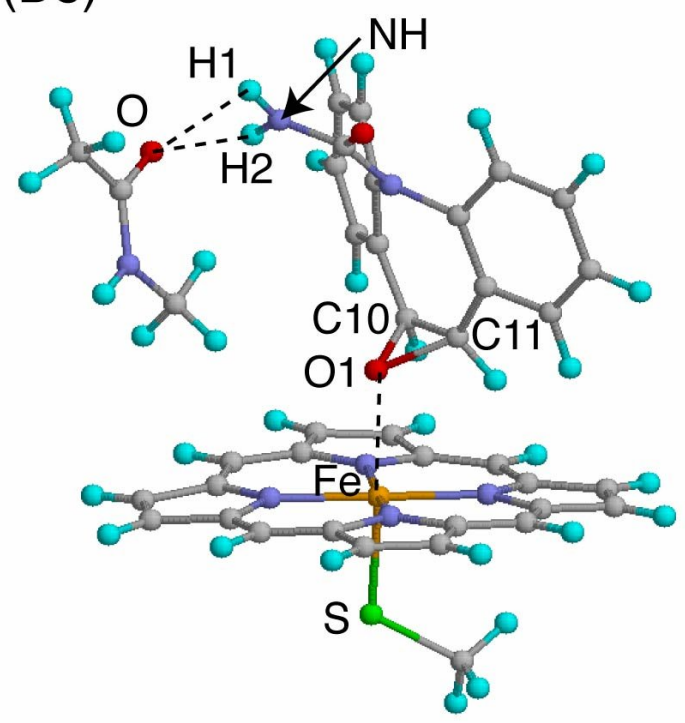

Figure 7 
(Q6)

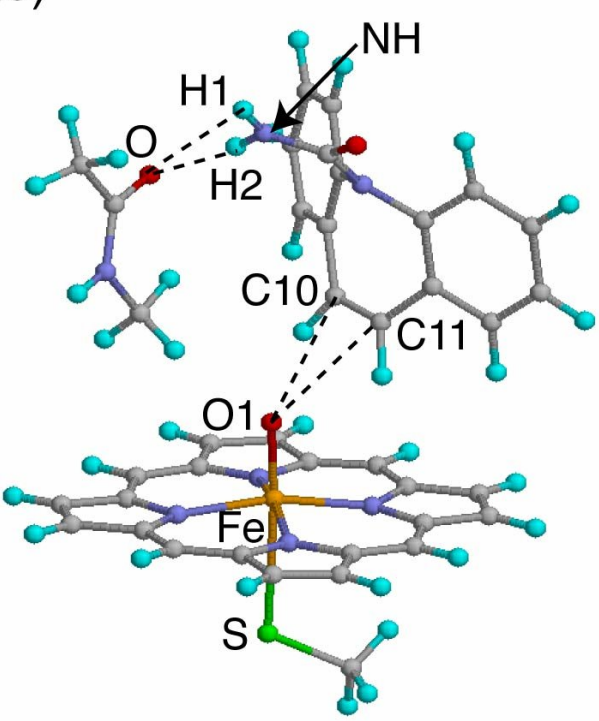

(Q7)

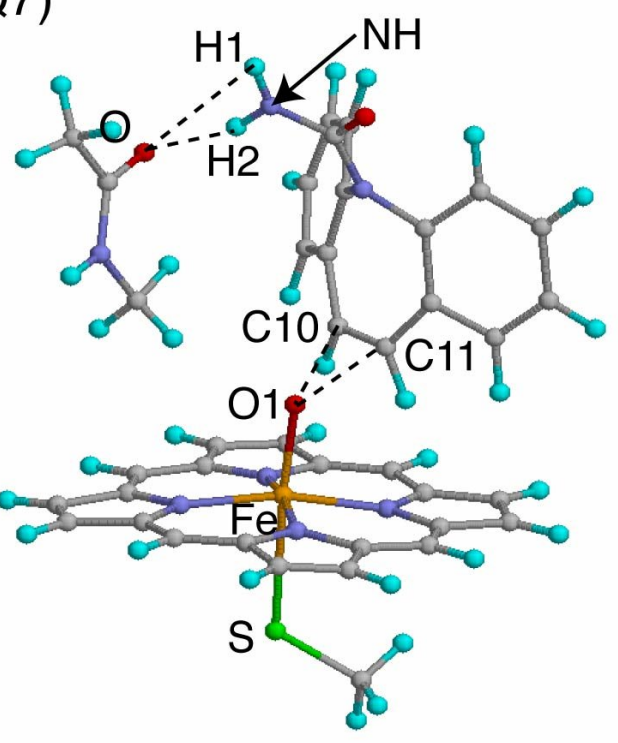

(Q8)

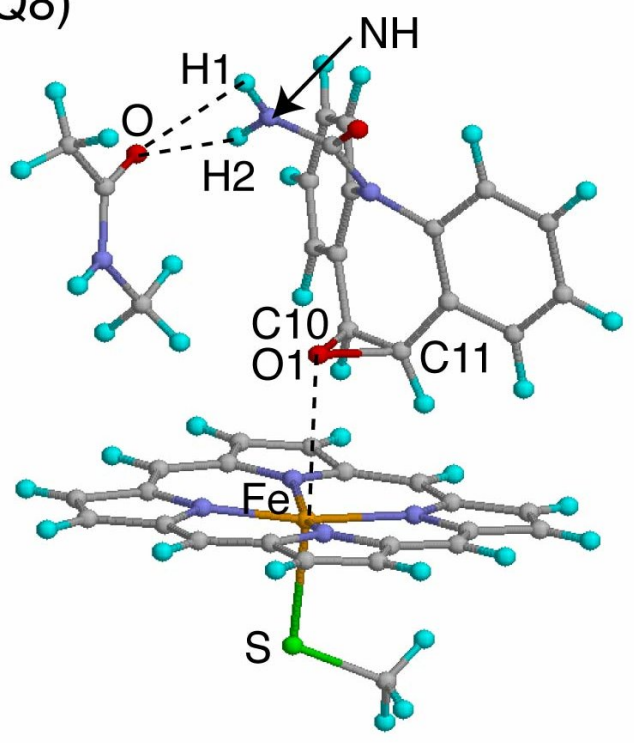

Figure 8 


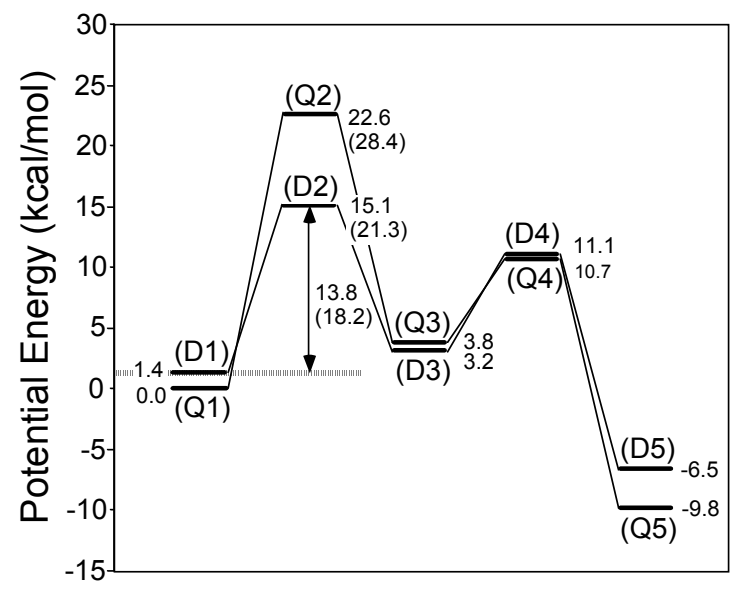

Figure 9 
(a)

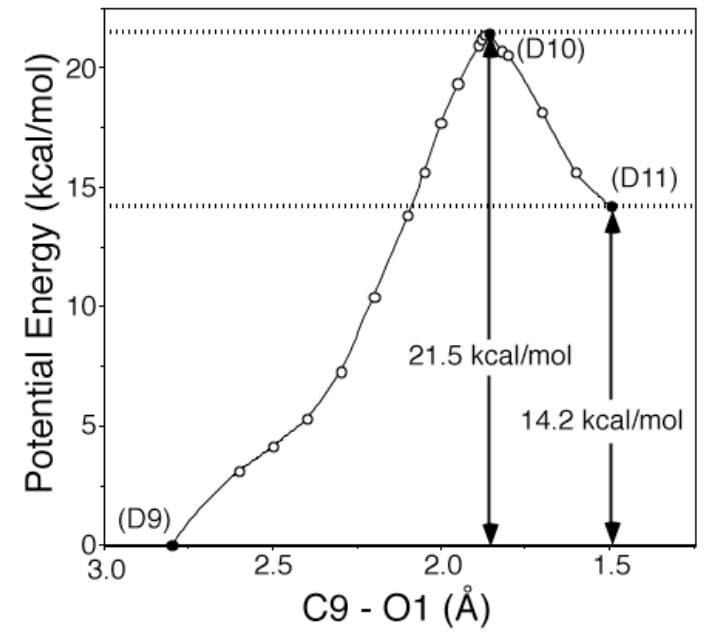

(b)

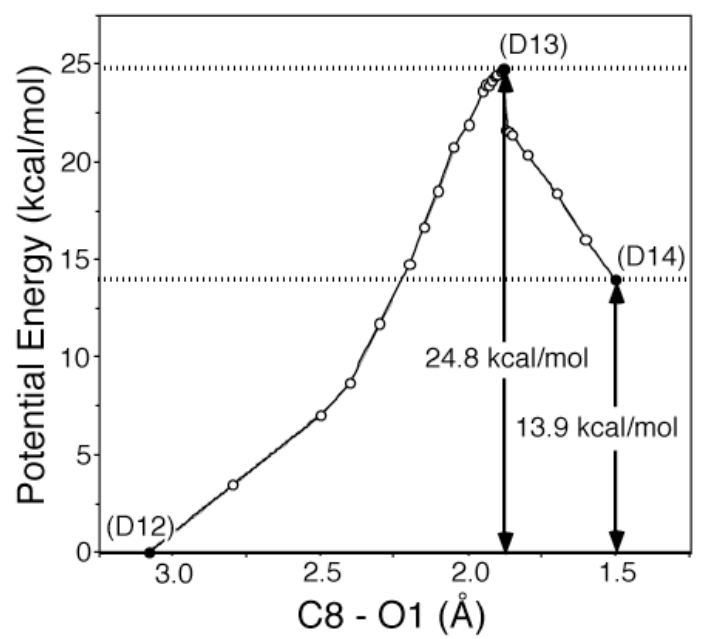

Figure 10 
(D9)

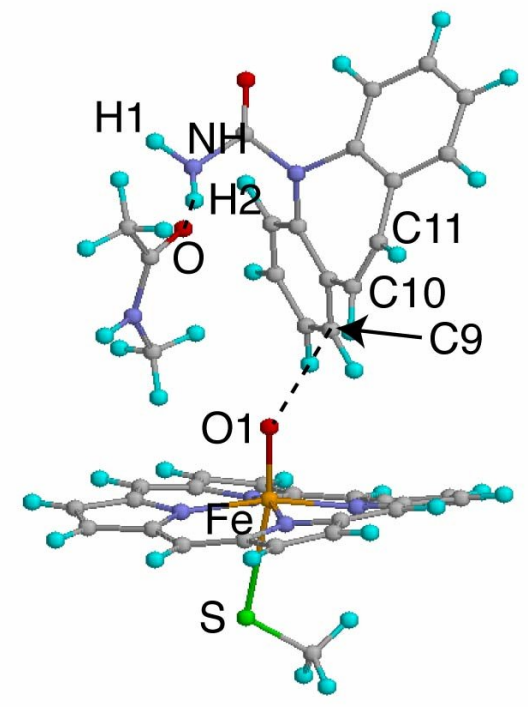

(D10)

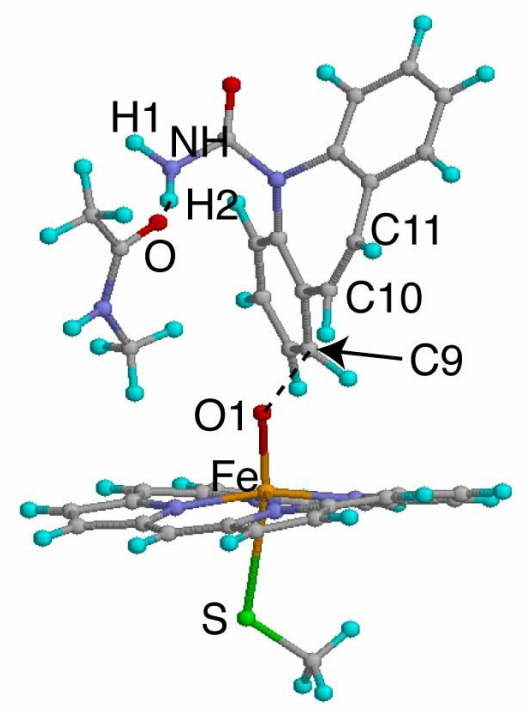

(D11)

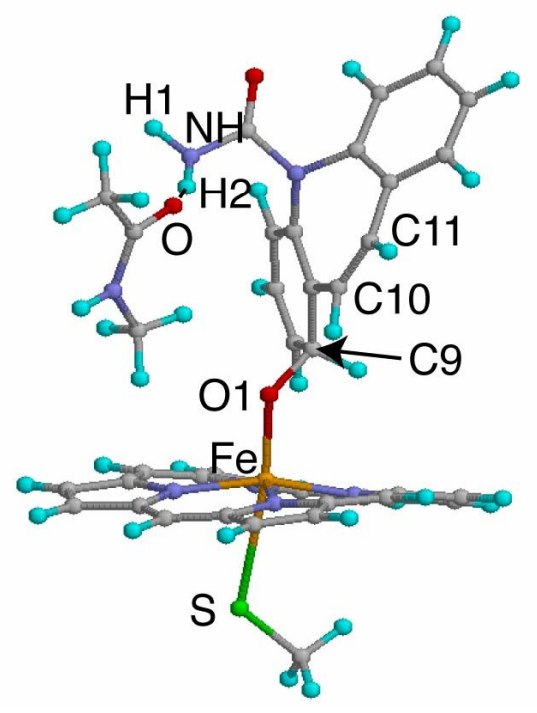

Figure 11 
(D12)

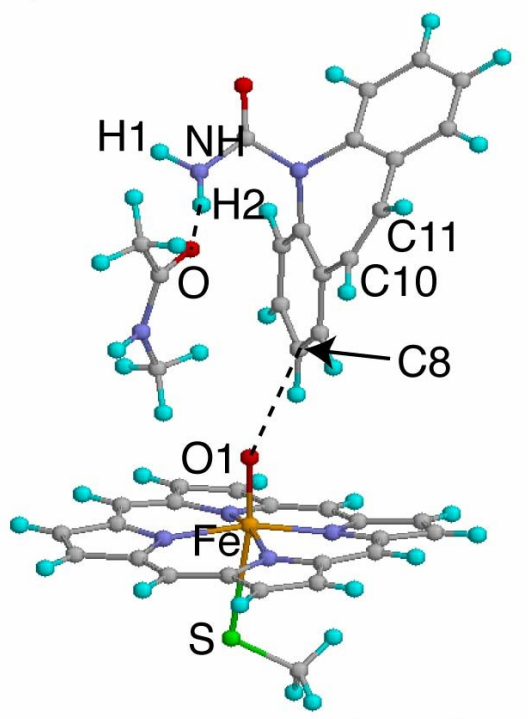

(D13)

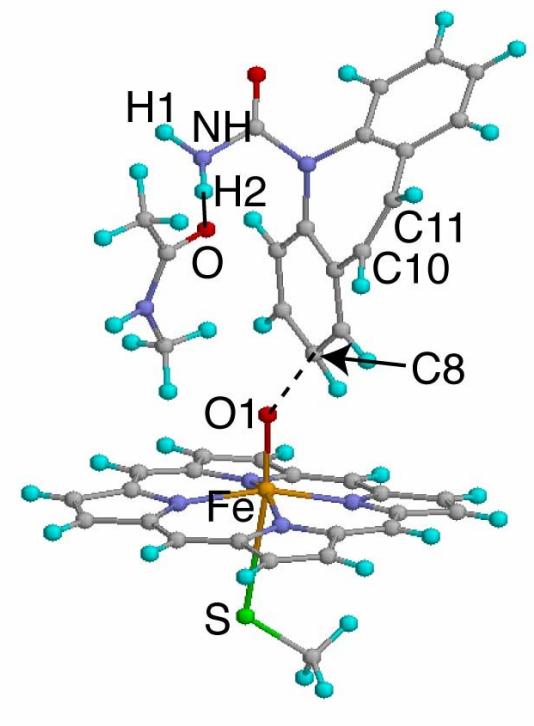

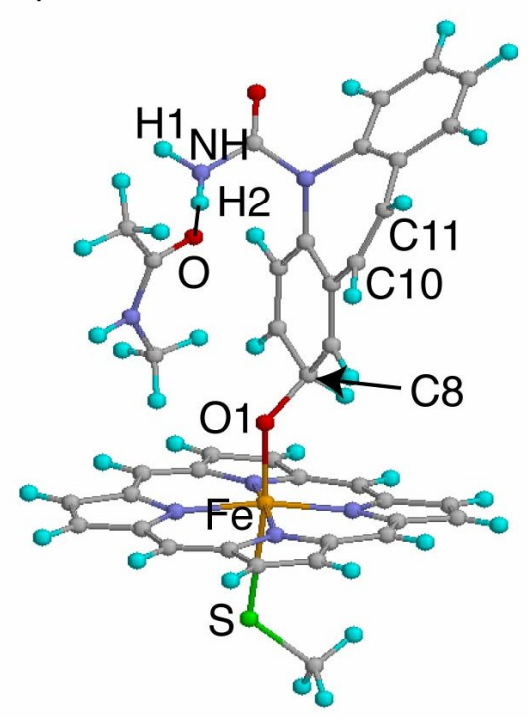

Figure 12 


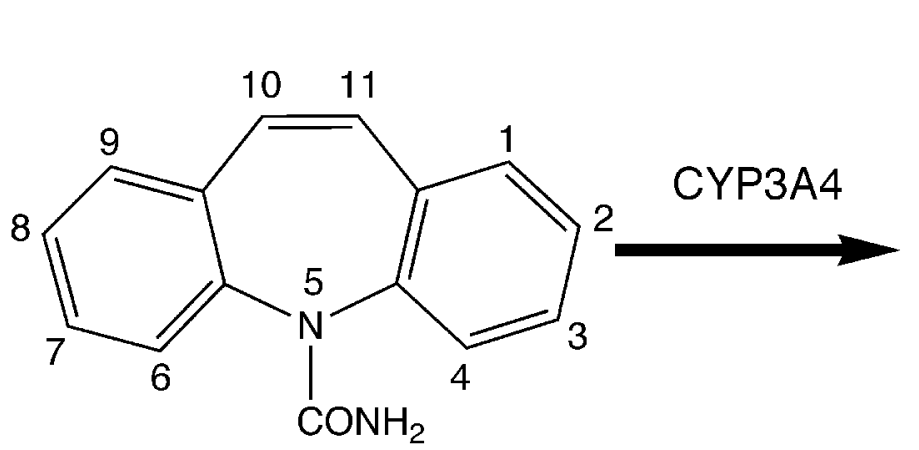

$\mathrm{CBZ}$

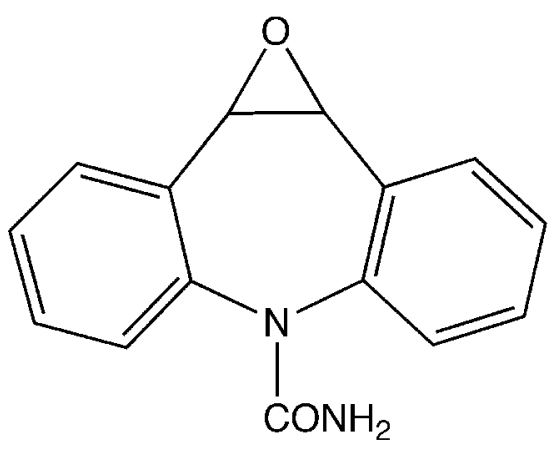

CBZ 10,11-epoxide

Scheme 1 

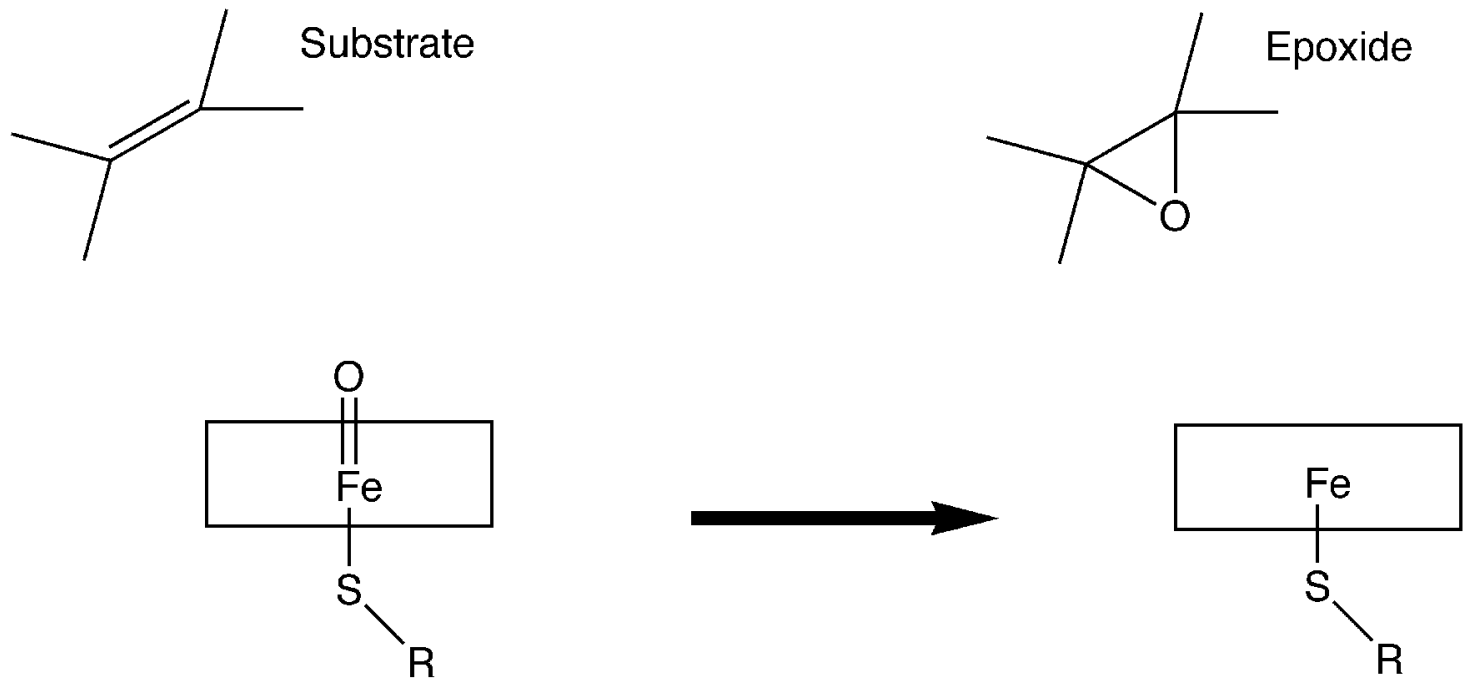

Compound I

Scheme 2 